\title{
QBO effects manifesting in ozone, temperature, and wind profiles
}

\author{
S. A. Sitnov \\ A. M. Obukhov Institute of Atmospheric Physics, Pyzhevsky 3, Moscow, 119017, Russia
}

Received: 6 June 2002 - Revised: 4 November 2003 - Accepted: 20 November 2003 - Published: 8 April 2004

\begin{abstract}
On the basis of ozonesonde records up to 1998 the responses on the equatorial quasi-biennial oscillation (QBO), manifesting in ozone, temperature, and wind (QBO effects) were isolated in the region from the ground to altitudes as high as $35 \mathrm{~km}$ at 22 stations located in Europe (7), North America (7), Japan (4), Hawaii (1), Australia (2), and Antarctic (1).
\end{abstract}

The vertical structures of the QBO effects of ozone are represented as an alternation of layers of well-developed quasibiennial signals, whose phases gradually change with height and thin transitional layers of ill-developed signals, whose phases change abruptly with height. The amplitudes of the effects depend on height and reach the maxima of 3-6 nbar in the lower stratosphere. At the majority of sites the effects are found to be approximately in phase between 20 and $23 \mathrm{~km}$.

Two types of the vertical structures of the temperature QBO effects are found. At most of the sites located equatorward of about $50^{\circ}$ the stratospheric temperature anomalies are characterized by downward propagation, whereas at sites situated poleward of about $50^{\circ}$ they look as columnlike structures. Near the tropopause the effects frequently reveal dipole-like structure, when the stratospheric and tropospheric anomalies are of opposite signs. The amplitudes of the effects are in the range of $0.5-1^{\circ} \mathrm{C}$.

The vertical structures of the QBO effects of horizontal wind components reveal a diversity of patterns. The amplitudes of the QBO effects of the meridional and zonal winds are comparable and lie in the range of $0.5-2 \mathrm{~m} \cdot \mathrm{s}^{-1}$. As a rule, the maxima of the effects are noticed slightly below the tropopause, as well as in the middle stratosphere.

In general, a statistical assurance of the obtained QBO effects is rather poor. However, a considerable part of them reveal similarity, which can be hardly explained by chance. Furthermore, the results agree with possible physical mechanisms of off-equatorial influence of the QBO, as well as with results of other observational studies.

Differences between the QBO effects obtained at different sites can be induced by peculiarities of corresponding ozonesonde records, differing by periods, gaps, number of

Correspondence to: S. A. Sitnov

(sitnov@ifaran.ru) sondes, errors of measurements, etc. Also, the differences can be associated with an inconstancy of characteristics of the equatorial QBO itself, as well as with an interdependency of the QBO and the annual cycle. Finally, the differences can reflect real regional characteristics of the QBO effects associated with local peculiarities of the large-scale circulation.

Key words. Meteorology and atmospheric dynamics (climatology; general circulation; middle atmosphere dynamics)

\section{Introduction}

Discovery of alternating regimes of westerly and easterly winds, descending with time in the equatorial stratosphere (Reed et al., 1961; Ebdon and Varyard, 1961), named because of their period by the term "quasi-biennial oscillation" (QBO) (Angell and Korshover, 1964) gave rise to numerous observational studies (e.g. Angell and Korshover, 1967; Hasebe, 1984, 1994; Dunkerton and Delisi, 1985; Bowman, 1989; Lait et al., 1989; Hollandsworth et al., 1995; Randel and Wu, 1996; Randel et al. 1999; Dunkerton, 2001), theoretical studies (Lindzen and Holton, 1968; Holton and Lindzen, 1972), and modeling studies (e.g. Plumb and Bell, 1982; Ling and London, 1986; Gray and Pyle, 1989; Tung and Yang, 1994; Hess and O'Sullivan, 1995; Hamilton, 1998), investigating this phenomenon in dynamical parameters and tracers, as well as its effects in low, middle, and high latitudes. Versatile and most complete up-to-date information about the QBO can be found in the comprehensive review of Baldwin et al. (2001).

Although the equatorial QBO has been studied rather extensively, our knowledge about its global effects is still rather fragmentary. In particular, we know little about the height dependence of the effects in middle and high latitudes. In this study, from several decades of ozonesonde measurements we attempt to isolate, describe, and systematize the vertical structures of the QBO effects, manifesting in ozone, temperature, and wind, as well as to explain some of their peculiarities by physical reasons. 


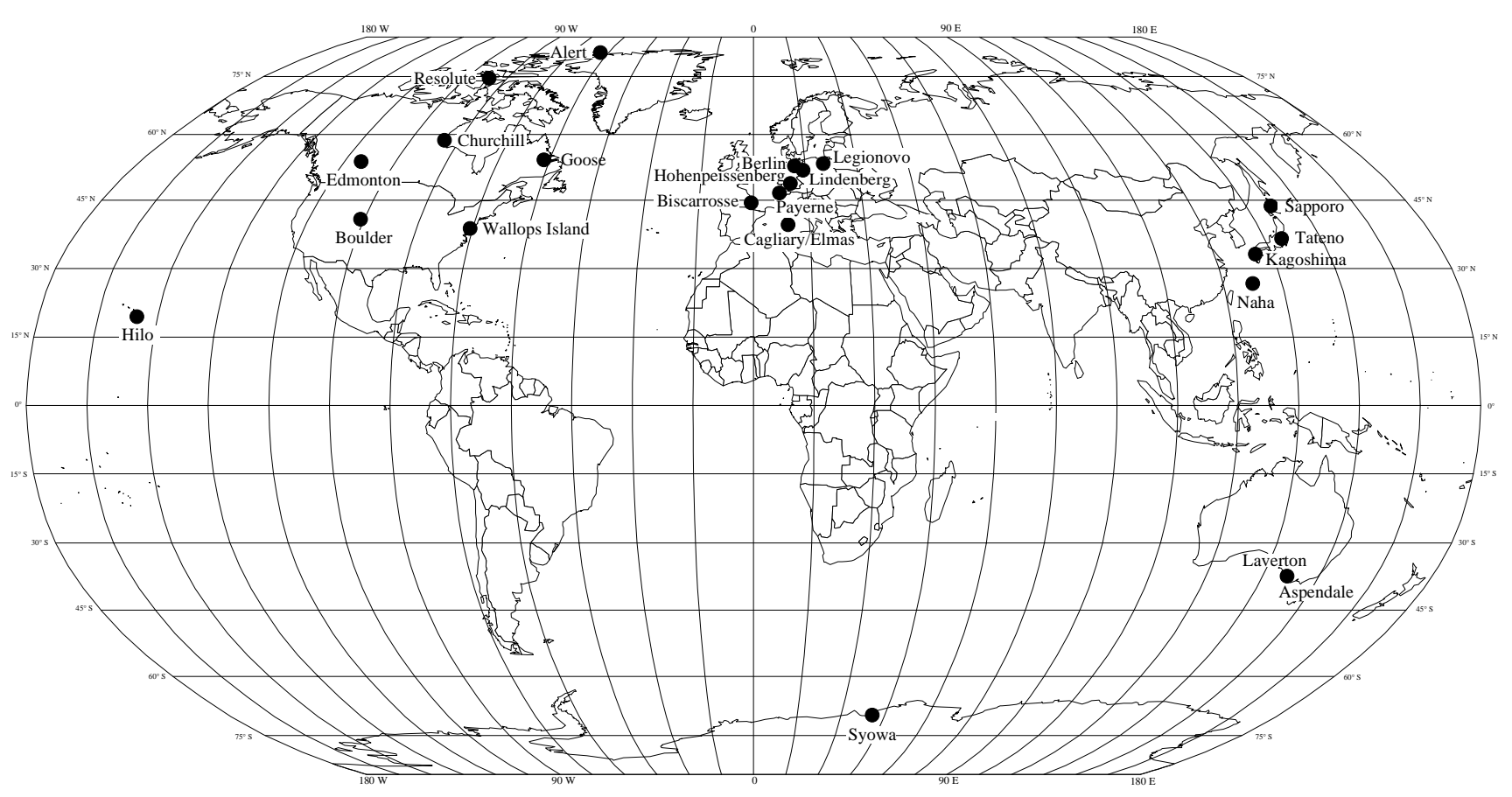

Fig. 1. Geographic location of the ozonesonde stations used in this work.

Table 1. Indicators of monthly means of ozone, temperature and wind profiles utilized.

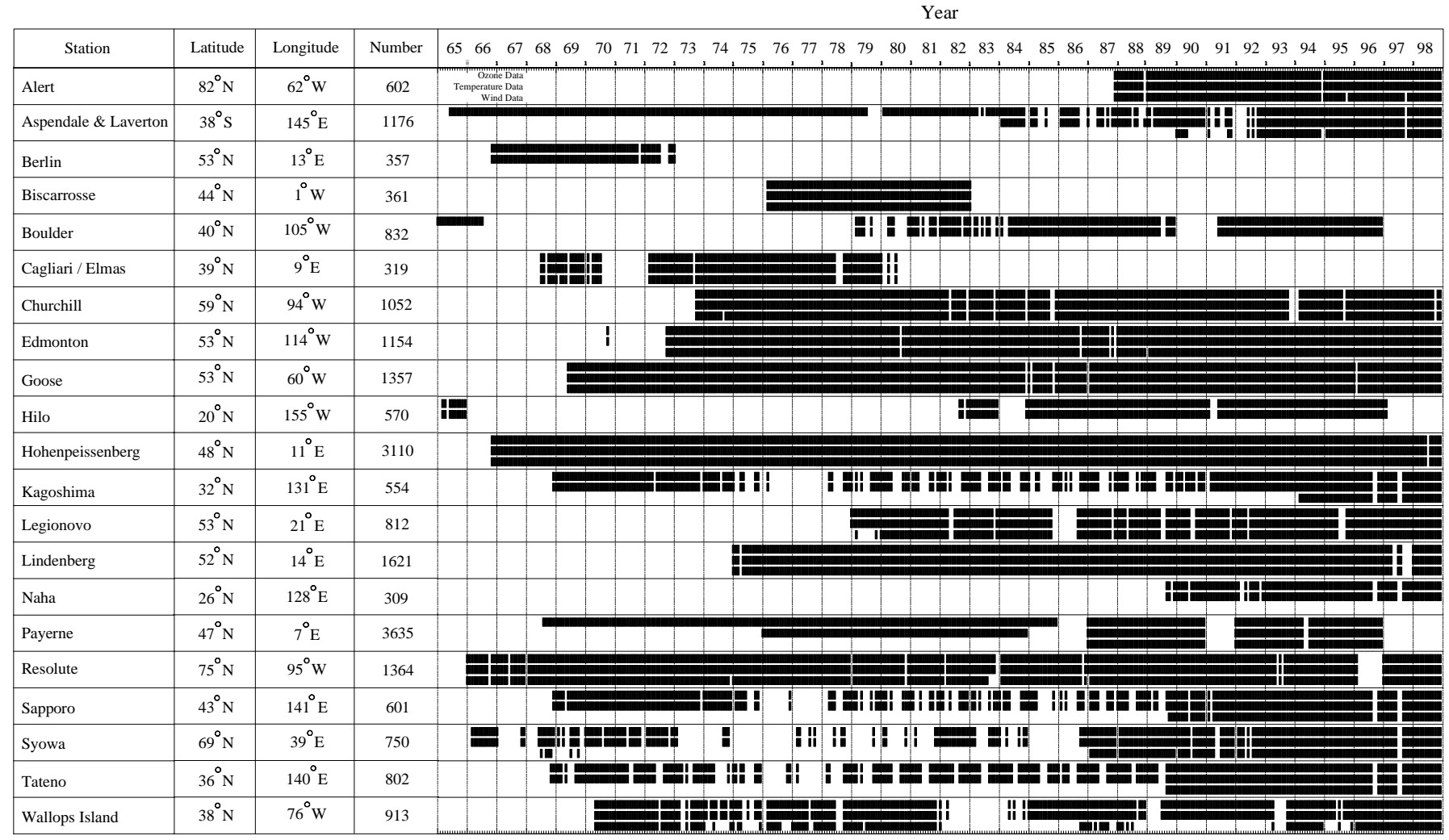

For each of the stations, from top to bottom, the indicators of available monthly means of ozone, temperature and wind are shown. Symbol | denotes that at least one profile of this parameter for a corresponding month exists. 


\section{Data}

Ozonesonde data was obtained from the World Ozone and Ultraviolet Radiation Data Center (WOUDC) archive, which is a part of the Global Atmosphere Watch programme of the World Meteorological Organization. The WOUDC archive is operated by the Meteorological Service of Canada and located in Toronto. The data are accessible through WOUDC FTP site ftp://woudc:woudc*@ftp.tor.ec. gc.ca/Archive-NewFormat/ozonesonde_1.0_1/.

Two basic types of electrochemical ozonesondes were used in balloon sounding - Brewer-Mast (BM) sondes (Brewer and Milford, 1960) and electrochemical concentration cell (ECC) sondes (Komhyr, 1969). Accuracy and precision of BM and ECC sondes are different. In general, ECC sondes give more self-consistent results than BM sondes (Logan, 1994). Barnes et al. (1985) reported that precision (standard deviation) of ECC sondes was found to be $6-10 \%$ from 800 to $200 \mathrm{hPa}, 5-6 \%$ from 200 to $10 \mathrm{hPa}$, and thereafter increased to $16 \%$ at $6 \mathrm{hPa}$, whereas accuracy was found to be $+(8-14) \%$ from 800 to $300 \mathrm{hPa},+(3-5) \%$ from 300 to $50 \mathrm{hPa}$, and about $+10 \%$ from 50 to $15 \mathrm{hPa}$. Still above, the accuracy changed its sign and reached $-17 \%$ at $6 \mathrm{hPa}$. There were several BM-ECC sondes intercomparison campaigns with rather different and even opposite results. De Backer et al. (1998) reported that when using the standard correction procedure there were significant negative (positive) differences between BM and ECC profiles above 40 (below 100) $\mathrm{hPa}$, respectively. Compared to the ECC sondes the BM gave $10-15 \%$ higher values in the troposphere, approximately the same results near the ozone maximum, and about $5 \%$ lower values at $10 \mathrm{hPa}$. However, it was also found that with the use of a temperature- and pressure-dependent correction procedure the differences between BM and ECC profiles become smaller than $3 \%$, i.e. insignificant. This indicated imperfection of the standard correction procedure. Taking into account this fact and to increase the number of ozonesonde data, in this paper no sonde selection based on the correction factor value was done.

The QBO attributed signals were successfully isolated at 22 ozonesonde stations, whose locations are displayed in Fig. 1. Table 1 displays indicators of utilized monthly mean profiles of ozone, temperature and wind. It is seen that ozonesonde records differ by periods of measurements, numbers of sondes, presence or absence of temperature and wind profiles, accompanying the ozone profiles, etc. Some of the records have large gaps. As a rule, observations of the same parameters obtained at different stations span different periods. On the other hand, it is seen that even at the same station ozone, temperature, and wind measurements can span different periods, too. When comparing the results, it is necessary to take into account this data inhomogeneity.

Monthly mean equatorial zonal wind data was taken from Naujokat (1986, with updates).

\section{Method}

All available ozonesonde readings, with the use of measured (if available) or model (Barnet and Corney, 1985) temperatures, were converted from $\mathrm{P}$ to $\mathrm{Z}$ system. With the help of linear interpolation the profiles were transferred onto a grid with heights equidistant in the range of $1-35 \mathrm{~km}$, with a step of $1 \mathrm{~km}$, and supplemented by ground readings. At each of the heights monthly mean values were calculated. The obtained time series were deseasoned by subtracting the longterm monthly means and then detrended. To reduce highfrequency variability and noise, as well as to suppress the remnants of the annual course the residuals were low-pass filtered by the 13-month running mean operator, to obtain interannual anomalies. Then, using the superimposed epoch method (Panofsky and Brier, 1958), the anomalies, having the same lags relatively the months of the E-W phase reverses of the 50-hPa equatorial zonal wind (key-0 data) were averaged. Statistical reliability of the average anomalies was estimated by using Student's t-statistics. The signals were treated as significant at the $95 \%(90 \%)$ confidence levels, if the $95 \%$ (90\%) confidence limits of their maxima and minima were not intersected. Finally, with the help of isolines the obtained individual height anomalies were combined to represent a time-height structure of the QBO effects.

\section{Results}

Figure 2 represents the obtained average anomalies at different sites, smoothed for clarity additionally by the 7-month running mean operator (that reduces the amplitude of the 28month sinusoidal signal by about $10 \%$ ). It is seen that most of the anomalies reveal a quasi-biennial periodicity, however, only a few of the signals are statistically significant. Because of this, when describing the results, particular attention will be paid to the similarity of the QBO responses, even if they are statistical insignificant, assuming that an accidental display of such similarity is unlikely. On the other hand, differences between the QBO effects must be treated carefully. They need further comprehensive analysis.

\subsection{Europe}

In spite of the lack of a unified QBO response of ozone there is a noticeable likeness between amplitudes and phases of the QBO responses manifesting in stratospheric ozone at the stations characterized by long records: Hohenpeissenberg, Payern, and Lindenberg, as well as (to a lesser degree) at Cagliari/Elmas (Fig. 2). The vertical structures of ozone anomalies reveal two regions of well-developed quasi-biennial signals - one in the lower stratosphere and another in the middle stratosphere, with amplitudes of about 5 and $3 \mathrm{nbar}$, respectively, and phases gradually changing with height. These regions are separated by a transitional layer in which quasi-biennial signals are small but their phases change abruptly with height. It is seen that anomalies manifested immediately over the transition lag those manifested 


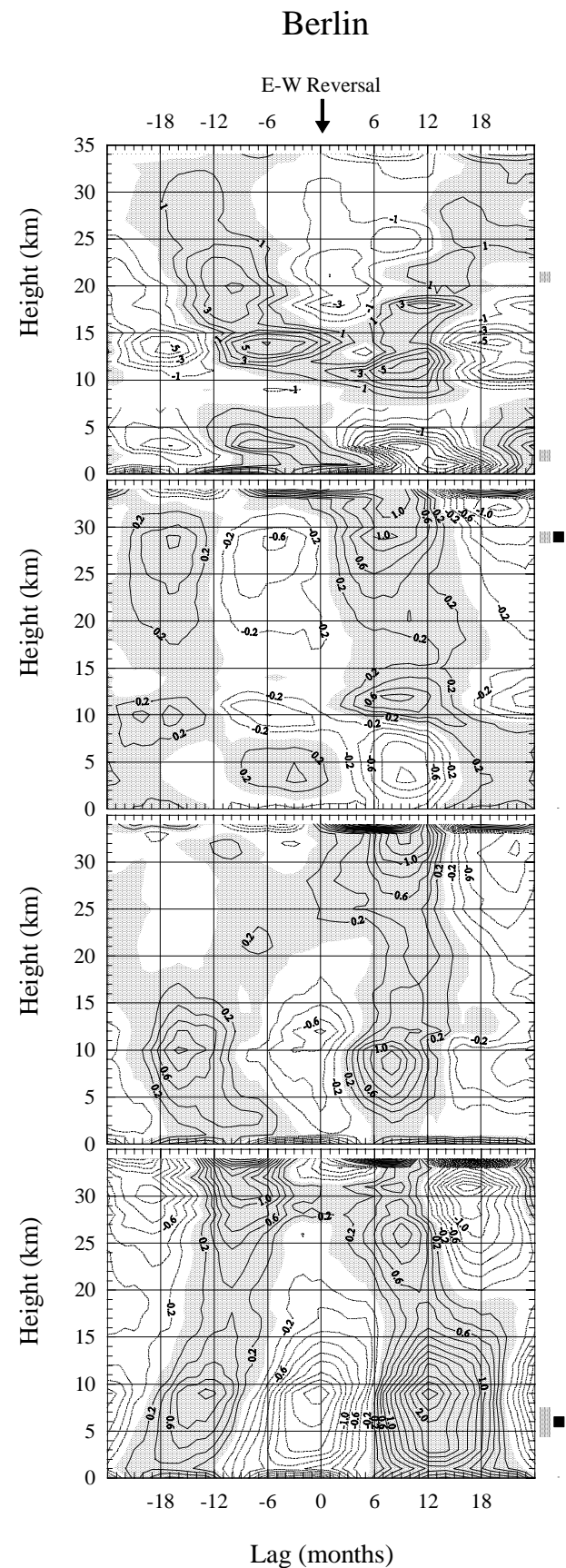

Contour interval in ozone is $1 \mathrm{nbar}$ (below $7 \mathrm{~km}-0.25 \mathrm{nbar}$ );

in temperature - 0.2 degrees;

in meridional and zonal winds $-0.2 \mathrm{~m} / \mathrm{s}$.
Legionovo
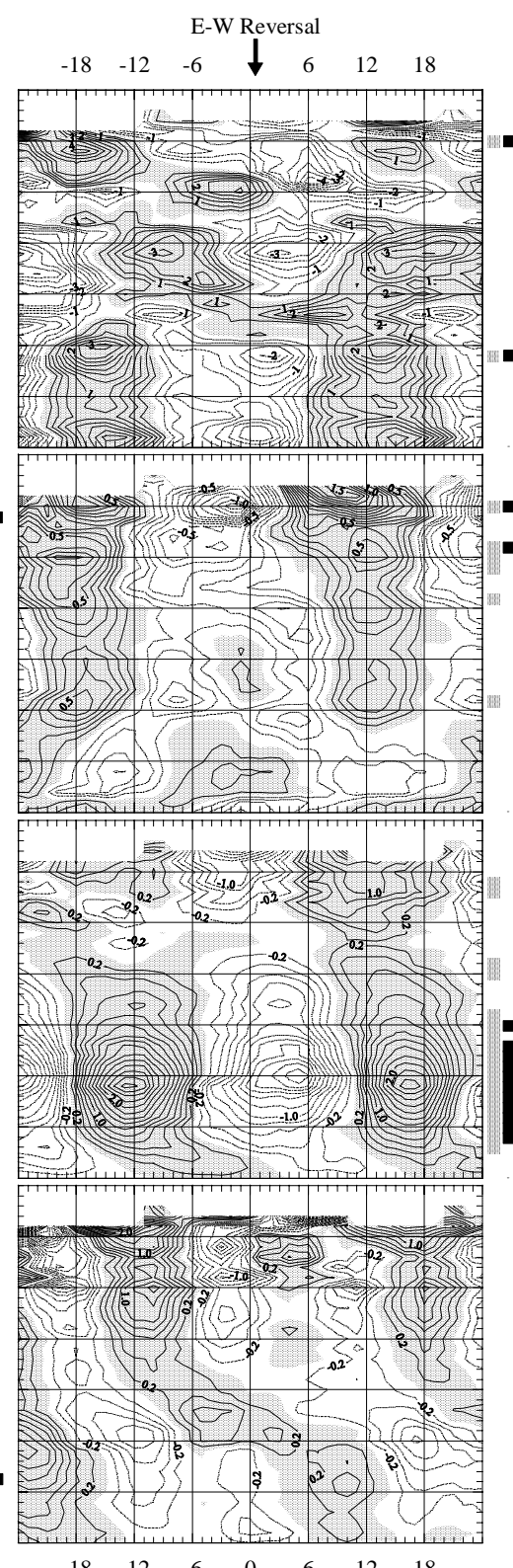

Lag (months)

Contour interval in ozone is 0.5 nbar (below $9 \mathrm{~km}-0.25 \mathrm{nbar}$ );

in temperature - 0.1 degrees;

in meridional and zonal winds $-0.2 \mathrm{~m} / \mathrm{s}$.
Lindenberg

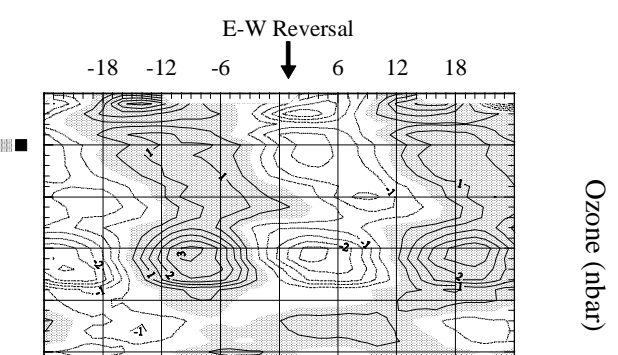

กิ

Fig. 2. Time-height sections of the QBO effects. Rows from top to bottom: ozone (nbar), temperature $\left({ }^{\circ} \mathrm{C}\right)$, meridional wind $\left(\mathrm{m} \cdot \mathrm{s}^{-1}\right)$, and zonal wind $\left(\mathrm{m} \cdot \mathrm{s}^{-1}\right)$. Zero isolines are omitted. Positive deviations in ozone and temperature, as well as northward and eastward winds are shaded. Lag is time in months relative to a month of the E-W phase reversal of the 50-hPa equatorial zonal wind. Black (grey) squares on the right sides mark the heights where 95\% (90\%) confidence levels of positive and negative anomalies, forming quasi-biennial signal are not intersected. 
Hohenpeissenberg

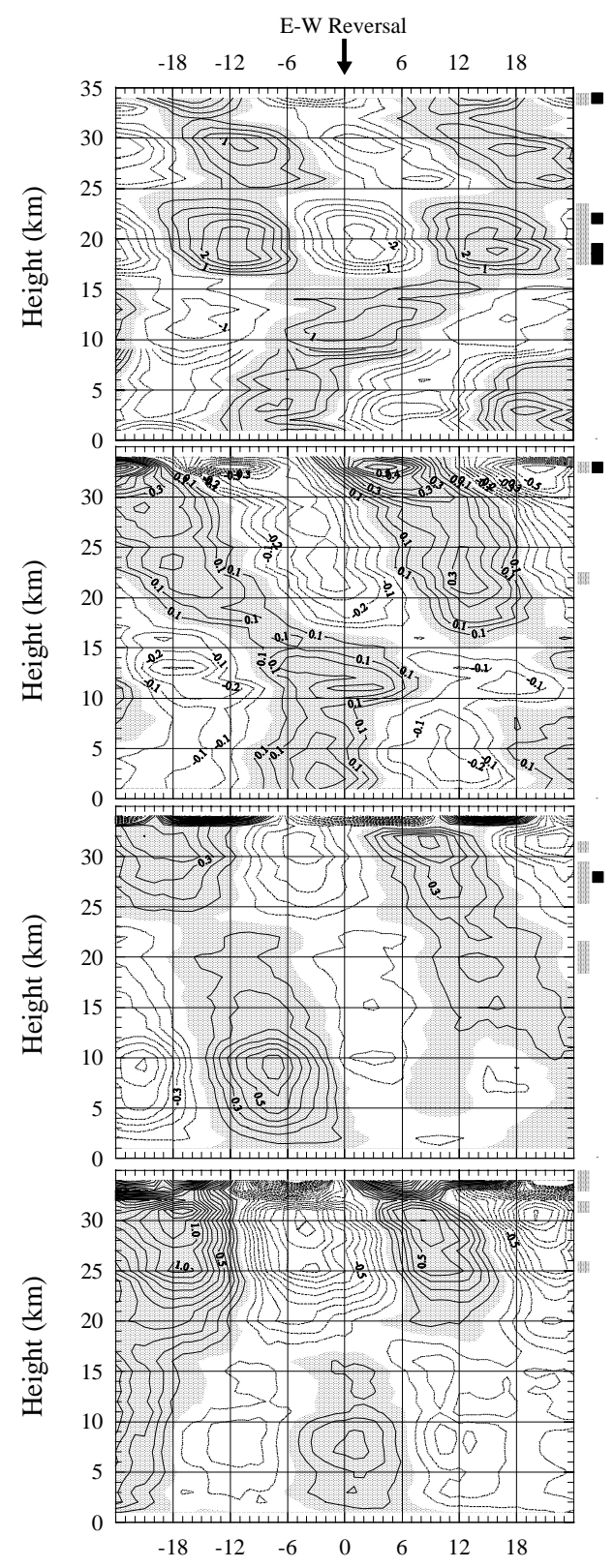

Lag (months)

Contour interval in ozone is $0.5 \mathrm{nbar}$ (below $9 \mathrm{~km}-0.1 \mathrm{nbar}$, above $25 \mathrm{~km}$ -0.25 nbar); in temperature - 0.1 degrees; in meridional and zonal winds $-0.1 \mathrm{~m} / \mathrm{s}$.
Payern

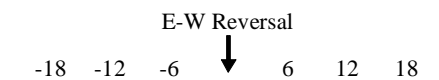

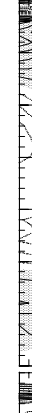
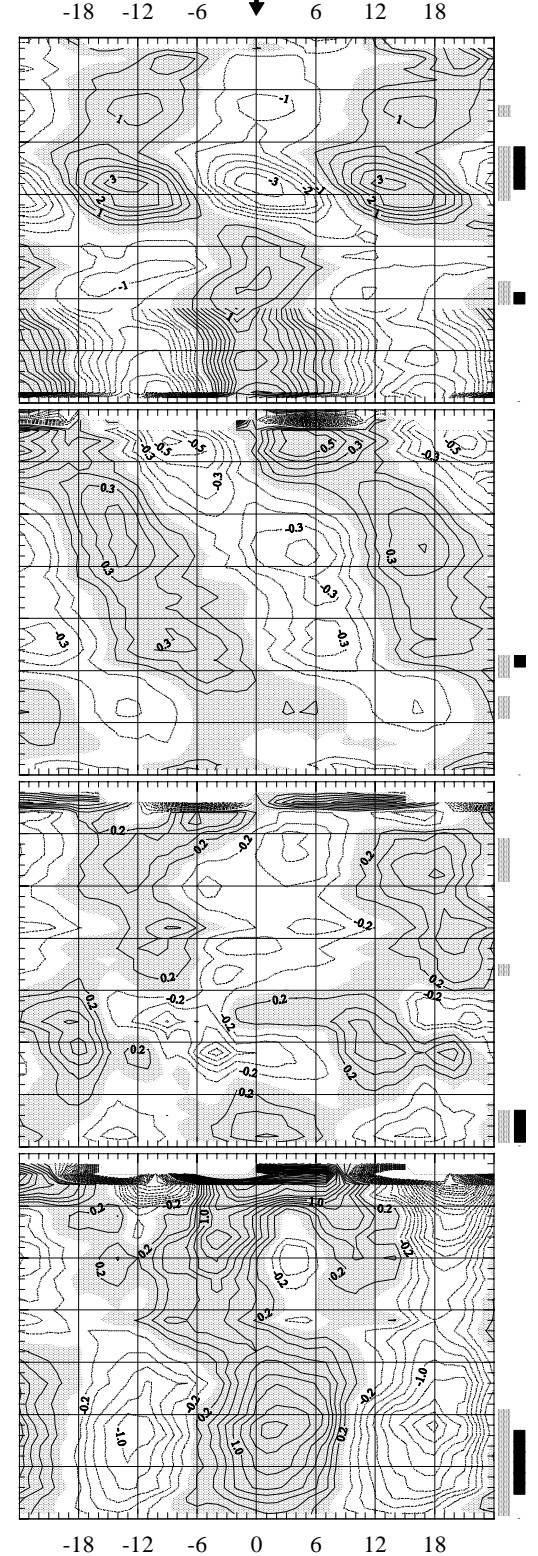

Lag (months)

Contour interval in ozone is 0.5 nbar (below $9 \mathrm{~km}-0.1 \mathrm{nbar}$ );

in temperature - 0.1 degrees;

in meridional and zonal winds $-0.2 \mathrm{~m} / \mathrm{s}$.
Biscarrosse
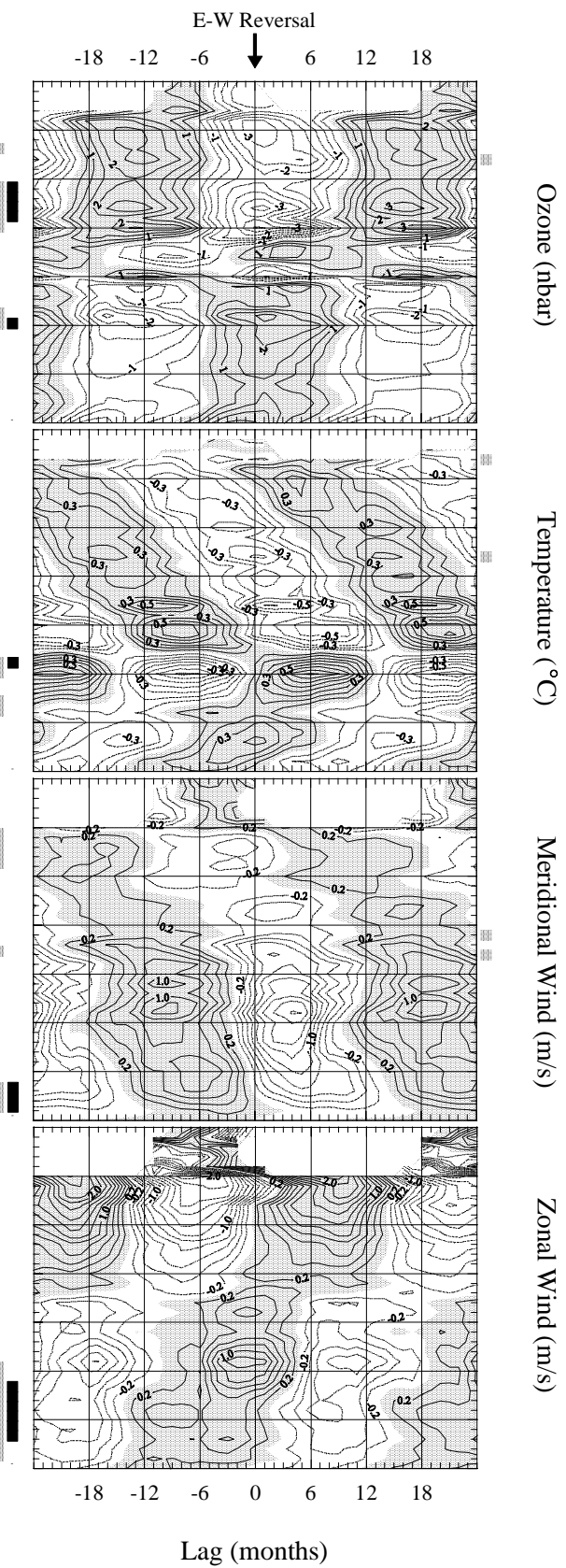

Contour interval in ozone is 0.5 nbar; in temperature - 0.1 degrees;

in meridional and zonal winds $-0.2 \mathrm{~m} / \mathrm{s}$.

Fig. 2. Continued. 


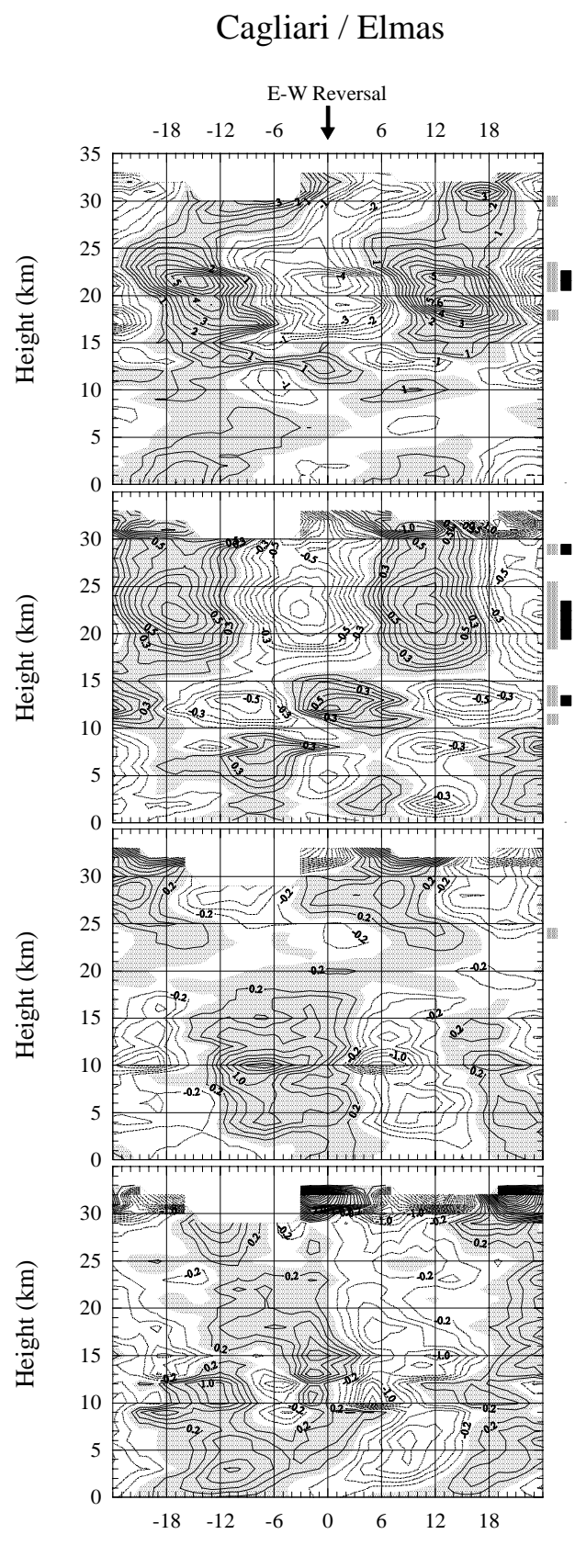

Lag (months)

Contour interval in ozone is $0.5 \mathrm{nbar}$; in temperature - 0.1 degrees;

in meridional and zonal winds $-0.2 \mathrm{~m} / \mathrm{s}$.
Alert

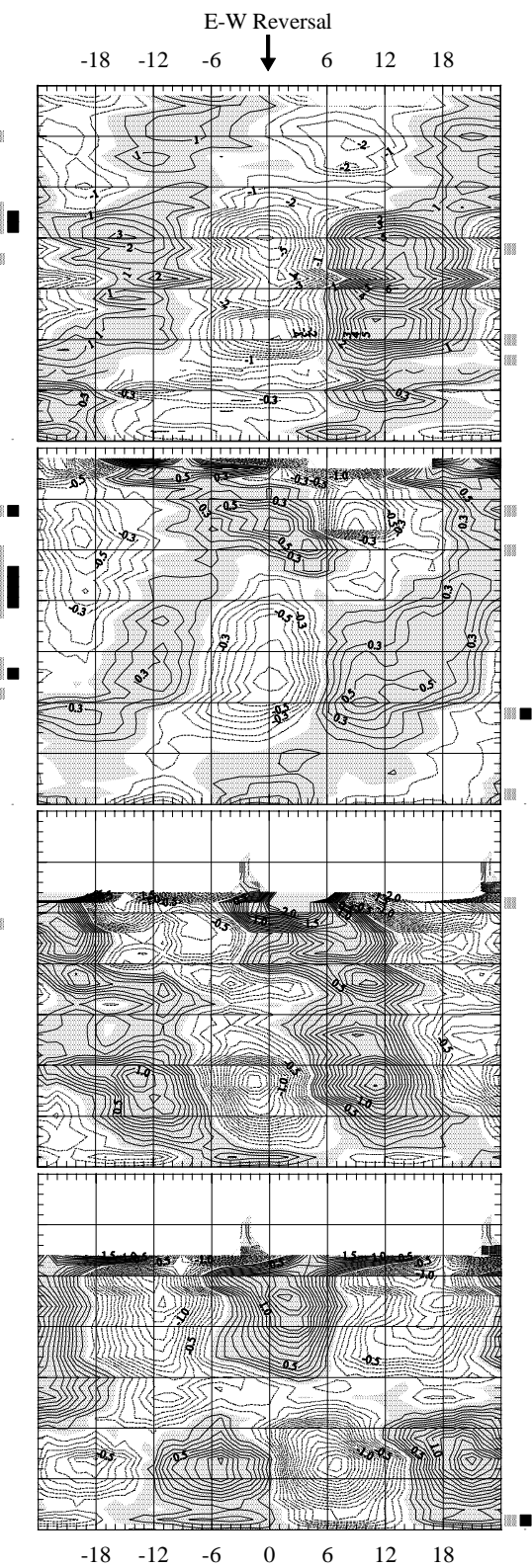

Lag (months)

Contour interval in ozone is 0.5 nbar (below $7 \mathrm{~km}-0.1$ nbar);

in temperature - 0.1 degrees;

in meridional and zonal winds $-0.1 \mathrm{~m} / \mathrm{s}$.
Resolute

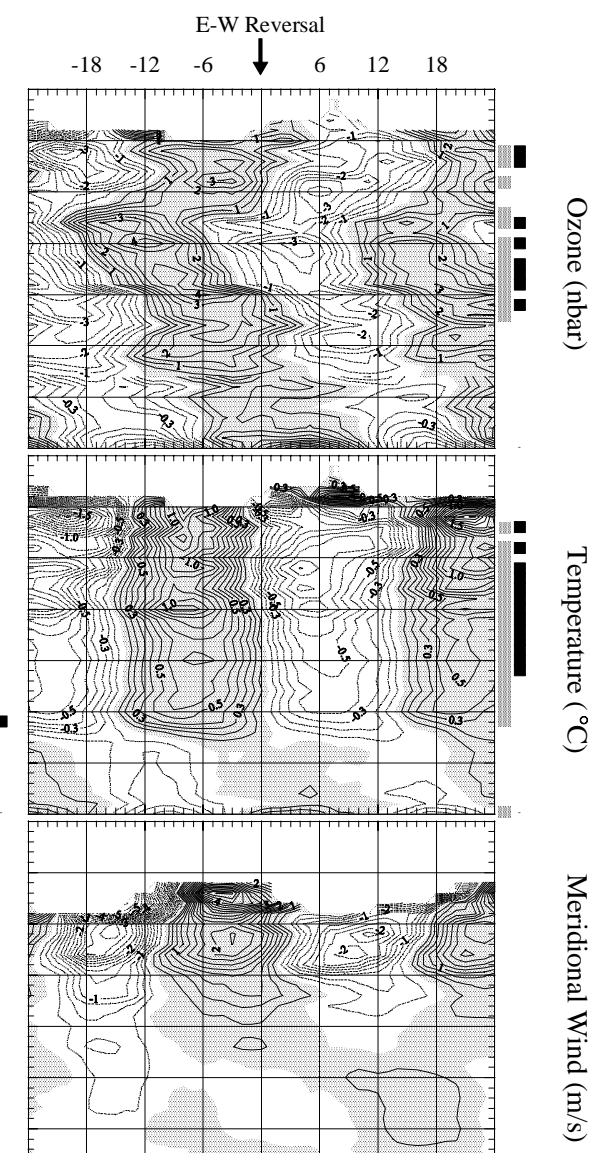

है

Fig. 2. Continued. 


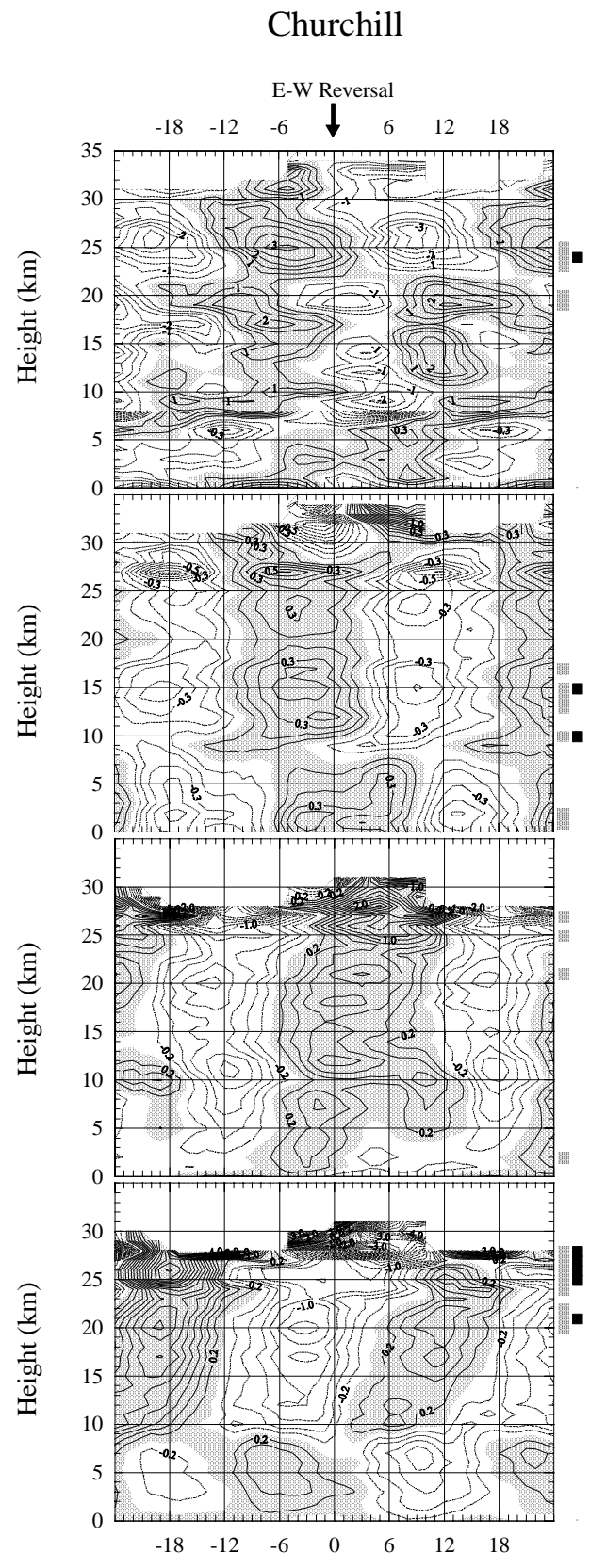

Lag (months)

Contour interval in ozone is $0.5 \mathrm{nbar}$ (below 8 km - 0.1 nbar); in temperature - 0.1 degrees; in meridional and zonal winds $-0.2 \mathrm{~m} / \mathrm{s}$.
Edmonton

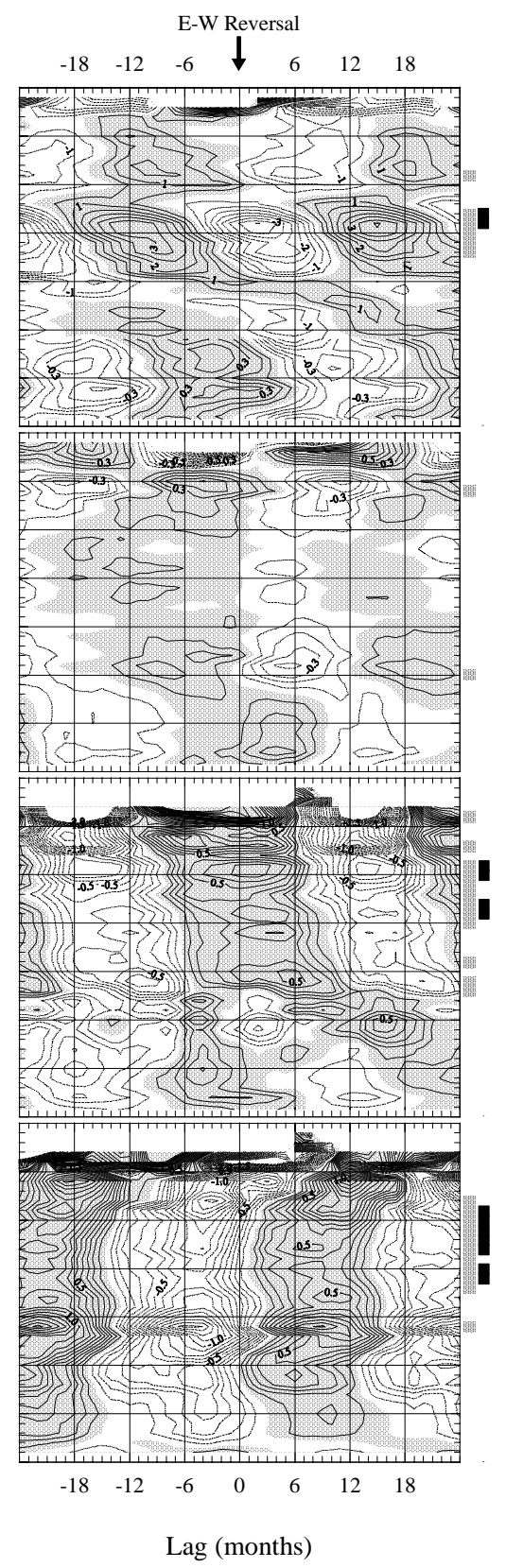

Contour interval in ozone is $0.5 \mathrm{nbar}$ (below 9 km - 0.1 nbar); in temperature - 0.1 degrees; in meridional and zonal winds - $0.1 \mathrm{~m} / \mathrm{s}$.

\section{Goose}

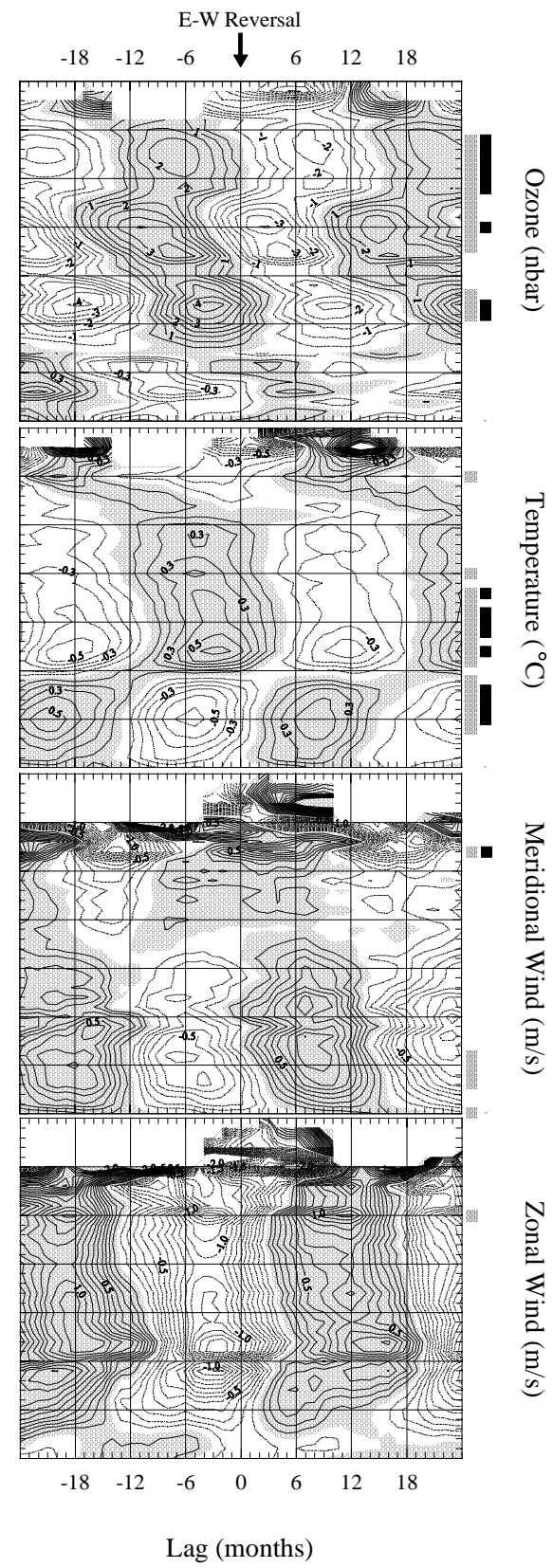

Contour interval in ozone is $0.5 \mathrm{nbar}$ (below $7 \mathrm{~km}-0.1 \mathrm{nbar}$ );

in temperature - 0.1 degrees

in meridional and zonal wind $-0.1 \mathrm{~m} / \mathrm{s}$.

Fig. 2. Continued. 


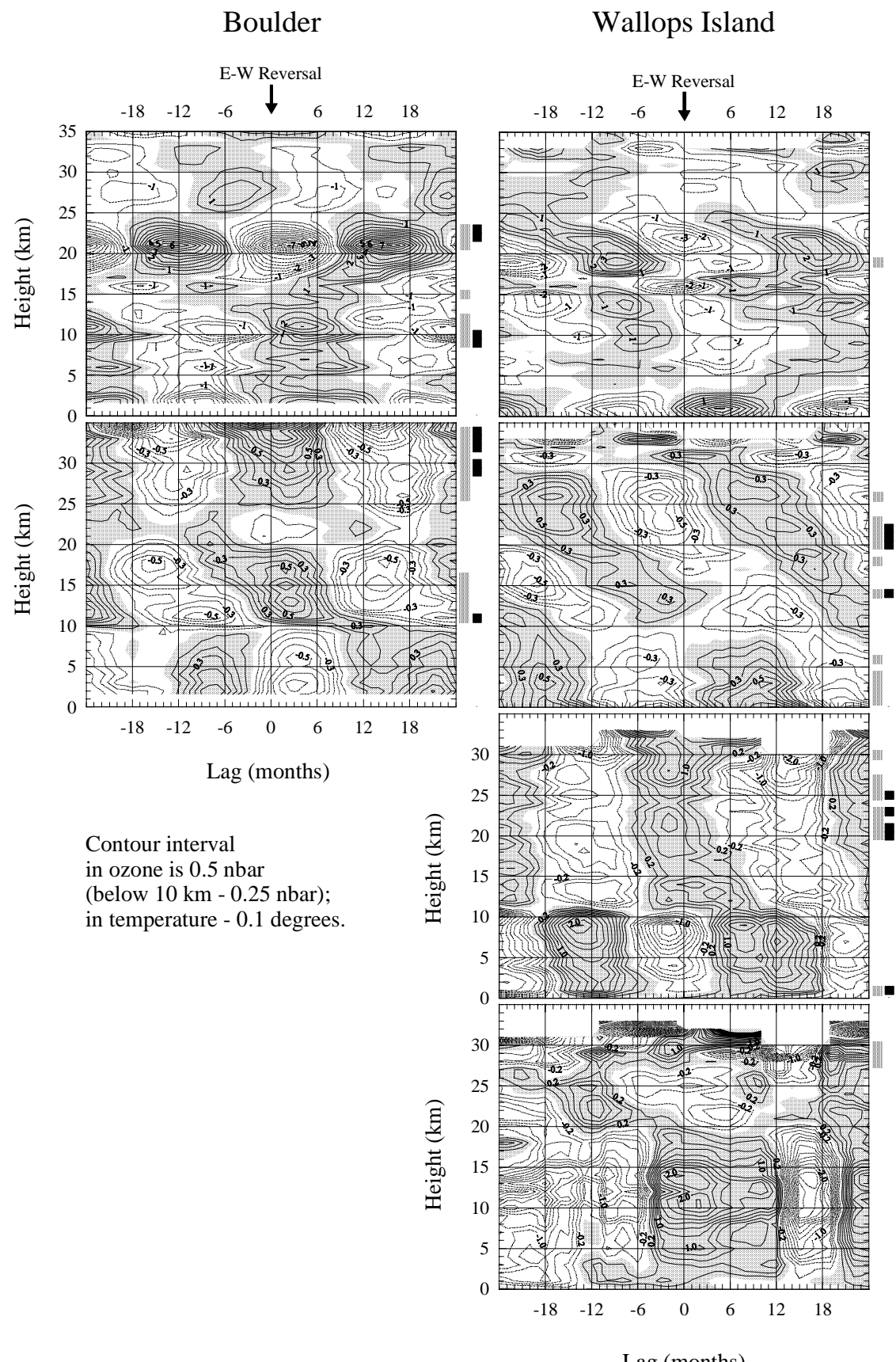

Lag (months)

Contour interval in ozone is 0.5 nbar (below 7 km - 0.25 nbar); in temperature - 0.1 degrees; in meridional and zonal winds $-0.2 \mathrm{~m} / \mathrm{s}$.
Sapporo
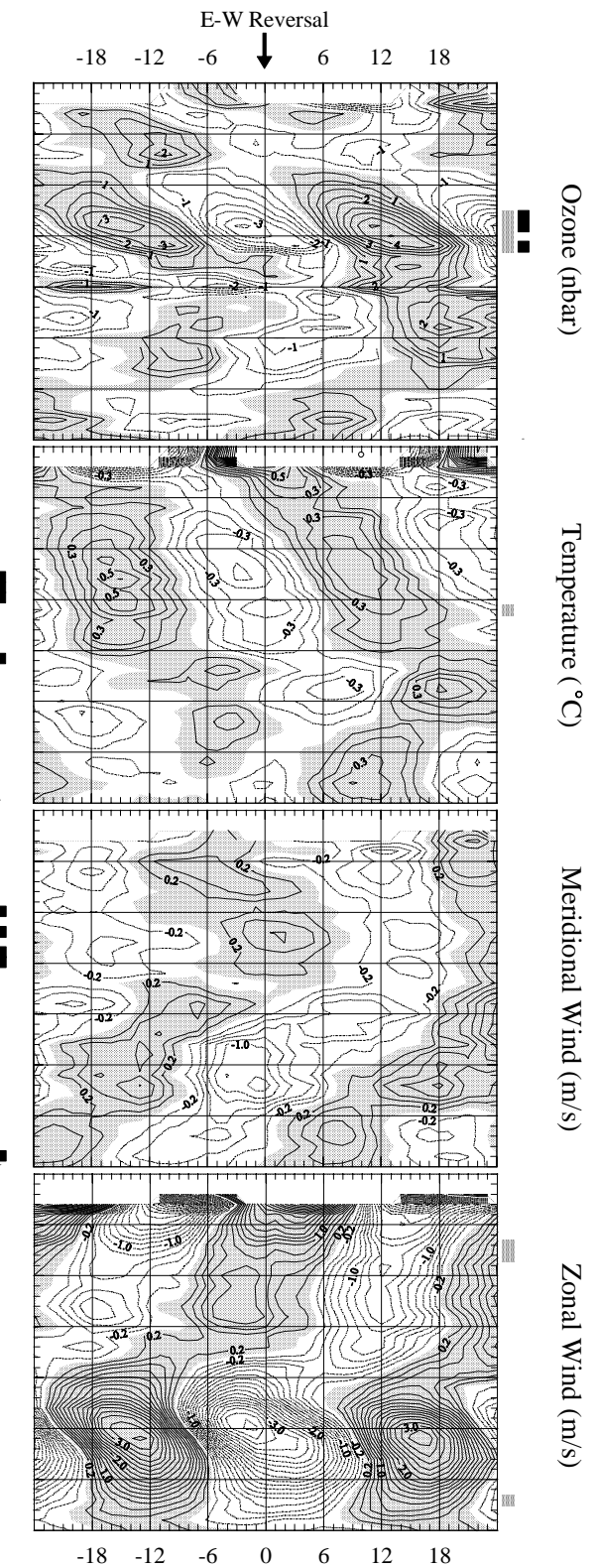

Lag (months)

Contour interval in ozone is $0.5 \mathrm{nbar}$ (below $9 \mathrm{~km}-0.25$ nbar); in temperature - 0.1 degrees; in meridional and zonal winds $-0.2 \mathrm{~m} / \mathrm{s}$.

Fig. 2. Continued. 


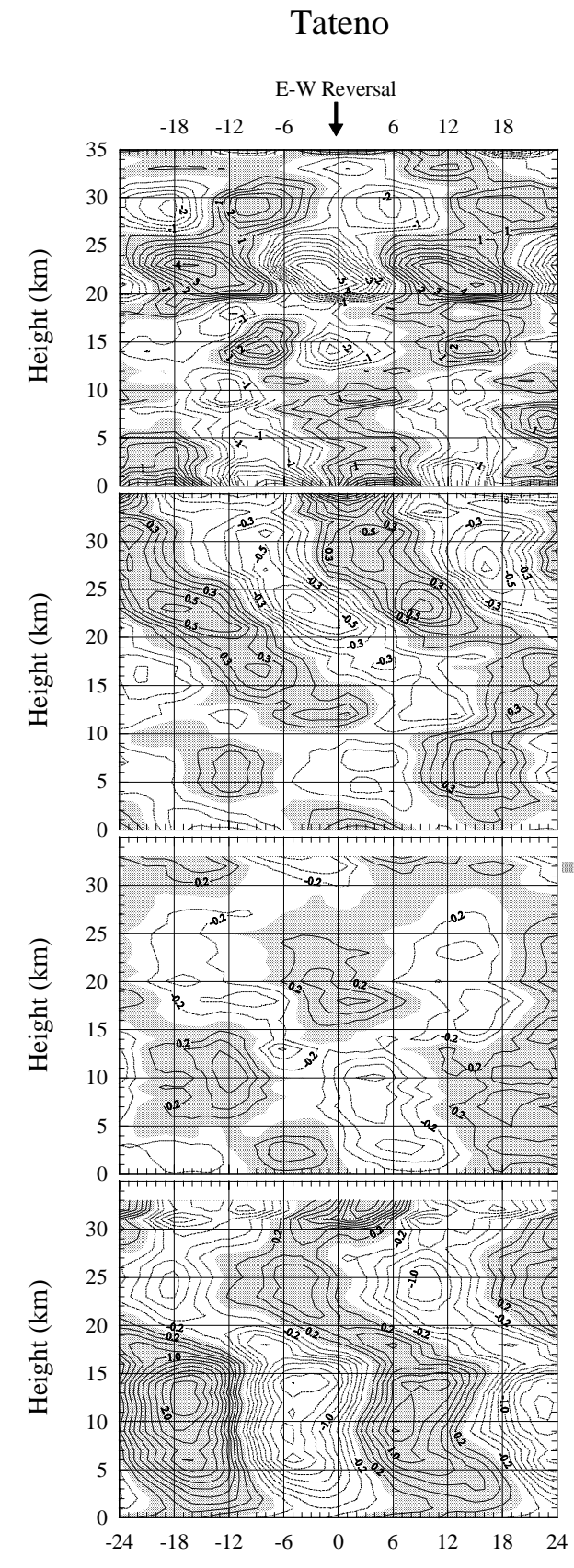

Lag (months)

Contour interval in ozone is 0.5 nbar (below $9 \mathrm{~km}-0.25 \mathrm{nbar}$ );

in temperature - 0.1 degrees;

in meridional and zonal winds $-0.2 \mathrm{~m} / \mathrm{s}$.
Kagoshima

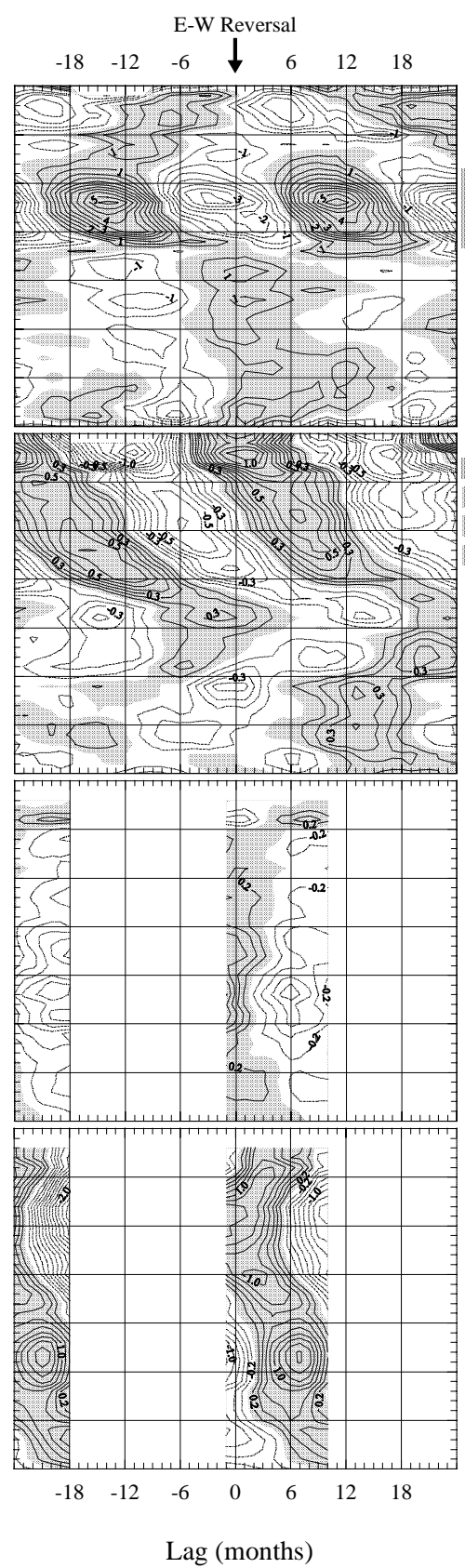

Contour interval in ozone is 0.5 nbar (below $9 \mathrm{~km}-0.25$ nbar);

in temperature - 0.1 degrees;

in meridional and zonal winds $-0.2 \mathrm{~m} / \mathrm{s}$.

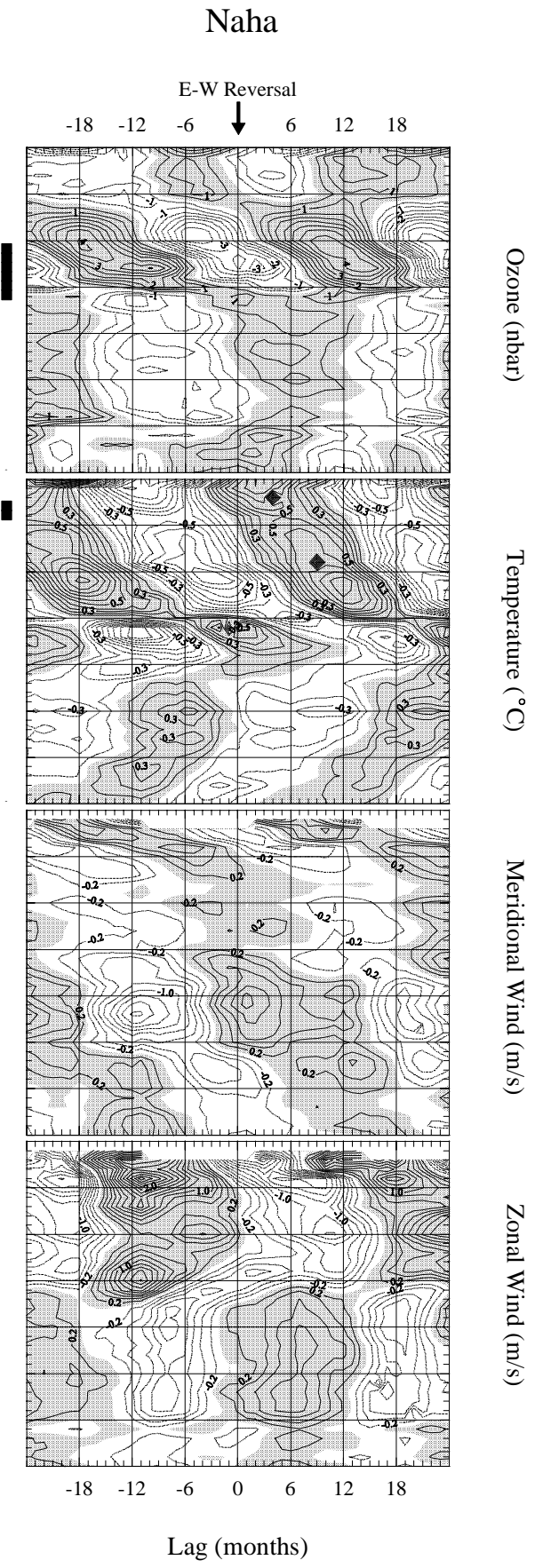

Contour interval in ozone is $0.5 \mathrm{nbar}$ (below $17 \mathrm{~km}-0.25 \mathrm{nbar}$ );

in temperature - 0.1 degrees;

in meridional and zonal winds $-0.2 \mathrm{~m} / \mathrm{s}$.

Fig. 2. Continued. 


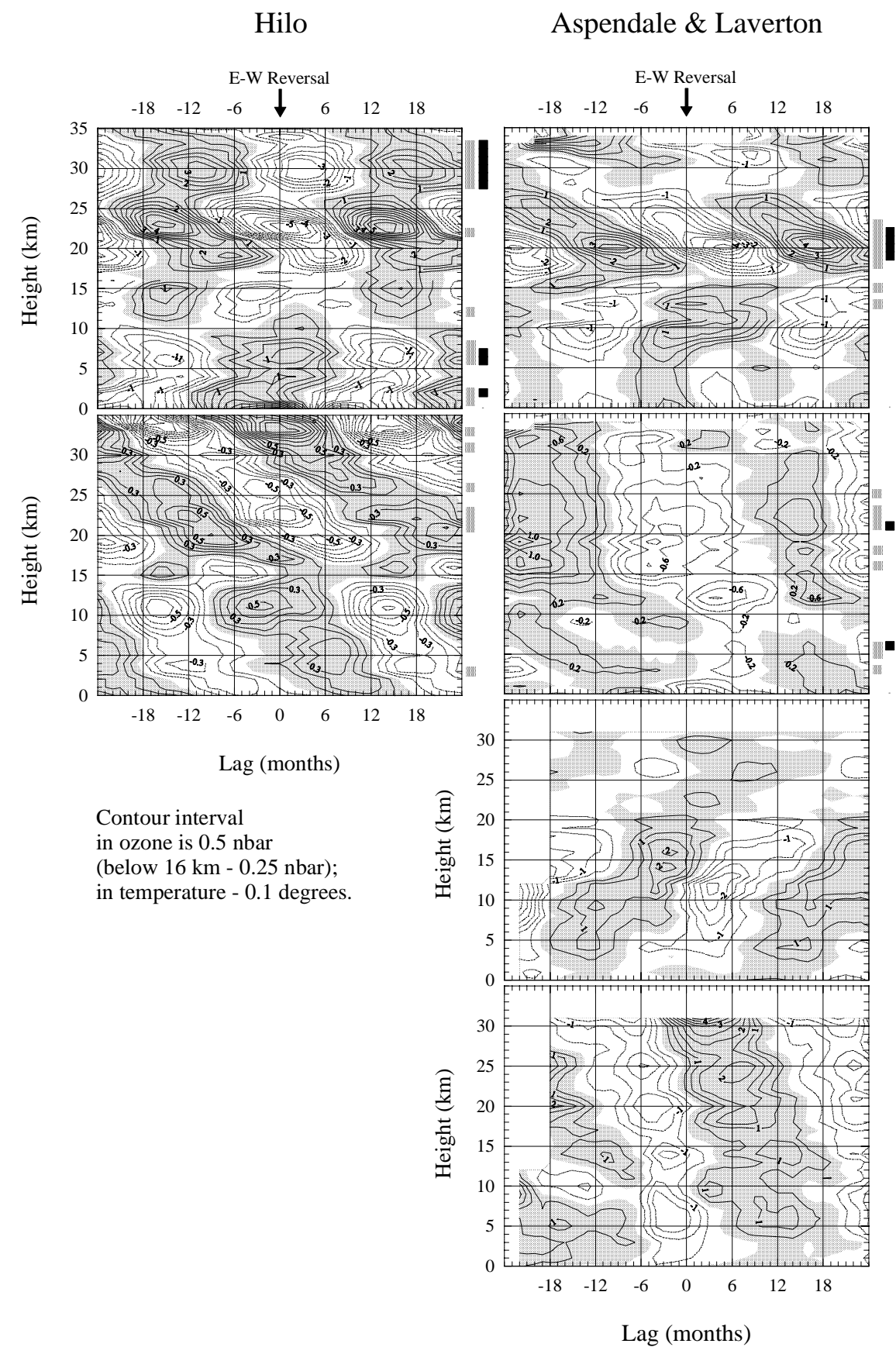

Contour interval in ozone is $0.5 \mathrm{nbar}$ (below $10 \mathrm{~km}-0.25 \mathrm{nbar}$ ); in temperature - 0.2 degrees; in meridional and zonal winds $-0.5 \mathrm{~m} / \mathrm{s}$.
Syowa

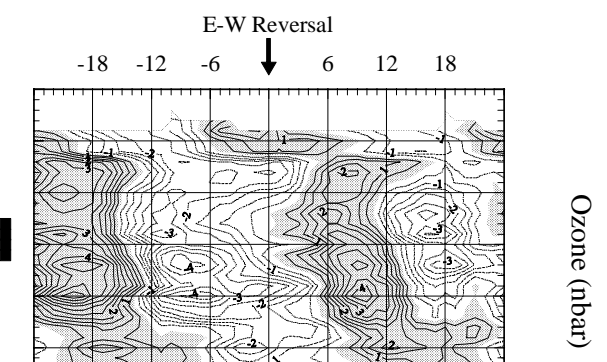

气

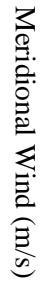

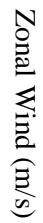

Fig. 2. Continued. 
immediately beneath it. There are some evidences of the existence of other transitional layers. Thus, at Lindenberg, Hohenpeissenberg, and Payern they can be traced at about $8 \mathrm{~km}$ and $16 \mathrm{~km}$, whereas between 10 and $15 \mathrm{~km}$ weak local maxima are displayed. In the lower stratosphere there is a hint of the downward propagation of the signals. Since at most of the European stations whose data were considered, the yearly mean tropopause is positioned at about $12 \mathrm{~km}$, the statistically significant quasi-biennial anomalies manifesting at heights $9-10 \mathrm{~km}$ at Legionovo and Payern give evidence for $\mathrm{QBO}$ responses, occurring in the tropospheric ozone.

Two different types of the QBO responses of temperature are found: at Hohenpeissenberg, Payern, and Biscarrosse the responses are characterized by downward propagation of anomalies with the rate of the phase descent of about $1 \mathrm{~km} \cdot$ month $^{-1}$, while at the rest of the stations stratospheric temperature anomalies reveal column-like structures. At all the European stations the phase differences between the anomalies, occurring between 20 and $30 \mathrm{~km}$, do not exceed 3 months. For both types of responses a monotonous height dependence is disturbed near the tropopause, and anomalies reveal a tendency to be in opposite phases in the lower stratosphere and in the troposphere. Some similarity of the tropospheric QBO responses can be found at Berlin, Legionovo, Lindenberg, and Hohenpeissenberg. Amplitudes of the QBO effects of temperature are in the range of $0.3-1{ }^{\circ} \mathrm{C}$.

The quasi-biennial signals of the meridional wind obtained at Legionovo, Lindenberg, Hohenpeissenberg and Biscarrosse have approximately the same phases between 25 and $30 \mathrm{~km}$. Also, there is a similarity between zonal wind anomalies at Lindenberg, Hohenpeissenberg and Biscarrosse, as well as at Payern (only below $17 \mathrm{~km}$ ). It is seen that the quasi-biennial signals of the meridional wind obtained at Lindenberg are significant from $7 \mathrm{~km}$ up to $30 \mathrm{~km}$, while those obtained at Legionovo (located at about $500 \mathrm{~km}$ distance east from Lindenberg) are significant from $4 \mathrm{~km}$ up to $15 \mathrm{~km}$. The anomalies at Legionovo and Lindenberg are approximately in phase, revealing the maxima at $10 \mathrm{~km}$, where the amplitudes of the signals reach the values of about $2.5 \mathrm{~m} \cdot \mathrm{s}^{-1}$ and $1 \mathrm{~m} \cdot \mathrm{s}^{-1}$, respectively.

It is difficult to elicit a single phase relationship between quasi-biennial anomalies of different parameters indention. As a rule, in the stratosphere temperature leads ozone by 36 months, with a tendency to increase the difference with height. Nearly the opposite phase relationships between the QBO responses of ozone and temperature are manifested above $30 \mathrm{~km}$ at Payern, as well as between 3 and $7 \mathrm{~km}$ at Legionovo and Lindenberg. Most of the positive (negative) anomalies of temperature, manifesting above $20 \mathrm{~km}$ at Legionovo, Lindenberg, Hohenpeissenberg, and Biscarrosse, are associated with south (north) wind, respectively (Fig. 2).

\subsection{North America}

The North American stations are more widely spaced than the European ones, representing the Arctic, middle latitudes, and a transitional zone between middle latitudes and the sub- tropics (Fig. 1). For all appearances, a geographic diversity of sites increases the differences between the QBO effects manifesting on them (Fig. 2). Nevertheless, the QBO responses obtained at the North American stations reveal a number of similar features.

At the majority of the stations there is a region, of several kilometers thick, centered at about $20 \mathrm{~km}$, where the most developed quasi-biennial signals of ozone exist, reaching the amplitudes of $6 \mathrm{nbar}$ (at Boulder). These signals differ in phases at most by 3 months and have minima timed to about the 50-hPa E-W equatorial QBO reverses. Over this region the signals reveal transitional layers. Above the transitions the well-developed quasi-biennial signals, characterizing by the time lag relatively signals revealing at $20 \mathrm{~km}$, manifest themselves again. At the mid-latitudinal stations the transitional layers can be also traced at heights $15-17 \mathrm{~km}$. Below $15 \mathrm{~km}$ there is a variety of quasi-biennial anomalies patterns. However, at Resolute and Goose a noticeable likeness between the QBO effects is clearly seen from the ground up until the middle stratosphere (it is noteworthy that at these sites most of the stratospheric signals are statistically significant). In particular, at both of the sites the anomalies reveal downward propagation below $22 \mathrm{~km}$. There is a hint on the downward propagation of the lower stratospheric ozone anomalies at Edmonton and Wallops Island. With the exception of Churchill and Edmonton, well-developed quasibiennial ozone anomalies can be seen in the troposphere, especially in its lower part, where they are approximately in phase (it is seen that at Boulder and Wallops Island the lower tropospheric signals reach the amplitudes more than $1 \mathrm{nbar}$, being, however, insignificant).

The quasi-biennial anomalies of temperature reveal nearly the opposite phase relation between the lower stratospheric and tropospheric anomalies. This peculiarity is most clearly seen at Goose, where the anomalies are statistically significant. At most of the stations the amplitudes of the QBO effects are in the range of $0.3-0.6^{\circ} \mathrm{C}$, while in the middle stratosphere at Resolute they exceed $1{ }^{\circ} \mathrm{C}$, being statistically significant. At Wallops Island the stratospheric anomalies reveal downward propagation with the rate of the phase descent of about $1 \mathrm{~km} \cdot \mathrm{month}^{-1}$. At the Arctic stations the local surface maxima of the quasi-biennial anomalies of temperature are observed.

At all the stations, above $20 \mathrm{~km}$, the phase differences between the quasi-biennial anomalies of the meridional wind do not exceed 6 months. At the mid-latitudinal Canadian stations stratospheric quasi-biennial anomalies of the zonal wind are in phase. In the same way the matters stand with those isolated at the Arctic stations. Amplitudes of the statistically significant signals of the horizontal wind components are in the range of $0.5-1 \mathrm{~m} \cdot \mathrm{s}^{-1}$.

Phase interrelations between QBO responses of different parameters vary between stations. Thus, at Alert the QBO responses of ozone and temperature are in phase above $5 \mathrm{~km}$. At the rest of the sites (with the exception of Boulder), in the regions where both the ozone and temperature QBO responses are well-pronounced, the phase differences between 
them do not exceed 3 months, but in contrary to the European stations the stratospheric effects of ozone often lead those in temperature. At Boulder above $25 \mathrm{~km}$ ozone leads temperature by about 8 months.

\subsection{Japan}

The quasi-biennial anomalies of ozone are well-developed in the regions 17-26 km at Sapporo, 19-26 km at Tateno, 19$27 \mathrm{~km}$ at Kagoshima, and $20-28 \mathrm{~km}$ at Naha. In the region $20-25 \mathrm{~km}$ the phase differences between anomalies, manifesting at the same height at these stations, do not exceed 3 months. The anomalies reach the amplitudes up to $5 \mathrm{nbar}$ (at Kagoshima) and reveal a hint of the downward propagation. Between 26 and $30 \mathrm{~km}$ the transitional layers of the signals become apparent. Above the transitions noticeable quasi-biennial ozone anomalies, characterizing by the time lag relatively those displaying in the region $20-25 \mathrm{~km}$, manifest themselves again. It is seen that the stratospheric anomalies are shifted, as a whole, to higher altitudes with the decrease of latitude. The transitional layers also exist in the region $15-20 \mathrm{~km}$. Below these transitions the vertical structures of the ozone anomalies substantially differ, nevertheless, it is seen, that the lower tropospheric anomalies are approximately in phase.

The vertical structures of temperature responses reveal the downward propagation of the stratospheric anomalies, as well as a hint of the upward propagation of the tropospheric anomalies. The rate of the phase descent of about $1.5 \mathrm{~km} \cdot \mathrm{month}^{-1}$ is noticed at Sapporo and twice as little as the others. The lower boundary of the region of the downward propagation of the anomalies reveals a tendency to be shifted to higher altitudes with the decrease in latitude that coincides with a tendency of the tropopause to be higher and colder with the decrease in latitude. The maximum amplitudes of the anomalies, exceeding $1^{\circ} \mathrm{C}$, are noticed in the middle stratosphere above Kagoshima, where the quasi-biennial signals are statistically significant, and of about $0.5^{\circ} \mathrm{C}$ at the rest of the stations.

Statistical provision of the quasi-biennial anomalies of wind is rather poor. Nevertheless, the anomalies of the zonal wind show some resemblance: there is almost an opposite phase relation between the lower stratospheric and tropospheric anomalies. In the troposphere the zonal wind anomalies reveal a tendency to be lagged and strengthened with the increase in latitude. The amplitudes of the anomalies reach the values of $0.8 \mathrm{~m} \cdot \mathrm{s}^{-1}$ at Naha, $1.6 \mathrm{~m} \cdot \mathrm{s}^{-1}$ at Kagoshima, $2.2 \mathrm{~m} \cdot \mathrm{s}^{-1}$ at Tateno, and $3 \mathrm{~m} \cdot \mathrm{s}^{-1}$ at Sapporo. Despite that the QBO responses of the meridional wind differ between stations, the quasi-biennial anomalies manifesting between 20 and $25 \mathrm{~km}$ are in phase.

Due to downward propagation of the temperature anomalies the phase relations between them and the ozone anomalies, vary with height. However, it is seen that the ozone and temperature anomalies are approximately in phase in the regions $15-26 \mathrm{~km}$ at Sapporo, $19-26 \mathrm{~km}$ at Tateno, $19-27 \mathrm{~km}$ at Kagoshima, and $20-30 \mathrm{~km}$ at Naha, whereas they are ap- proximately in antiphase in the regions from the ground to altitude of $15 \mathrm{~km}$ at Sapporo and Naha, as well as above 26, 27 and $30 \mathrm{~km}$ at Tateno, Kagoshima, and Naha, respectively.

\subsection{Hawaii}

The vertical structure of the ozone anomalies at Hilo reveal five regions of well-developed quasi-biennial signals, centered at the surface, as well as at the heights of 7, 15, 23, and $30 \mathrm{~km}$, with the amplitudes of 2, 1, 1, 5, and $3 \mathrm{nbar}$, respectively. These regions are separated by transitional layers centered at the heights of 5,11, 17, and $27 \mathrm{~km}$. Between 18 and $26 \mathrm{~km}$ the ozone anomalies reveal downward propagation. The anomalies manifesting immediately above the 17- and 27-km transitions lag those manifesting immediately below. Nevertheless, on the whole, the QBO responses manifesting above and below $11 \mathrm{~km}$ are approximately in opposite phases.

The quasi-biennial signals of temperature clearly reveal themselves in the range of heights from the ground up to $35 \mathrm{~km}$, manifesting downward propagation with the rate of the phase descent of about $0.7 \mathrm{~km} \cdot \mathrm{month}^{-1}$ in the stratosphere and approximately twice as much in the troposphere. The signals reveal the local maxima at the heights of 11, 22, and $33 \mathrm{~km}$, where the amplitudes of the signals are about 0.5 , 0.6 , and $1^{\circ} \mathrm{C}$, respectively.

The quasi-biennial anomalies of ozone and temperature are in phase in the regions $18-26 \mathrm{~km}$ and in opposite phase above $27 \mathrm{~km}$.

\subsection{Australia}

The QBO effect of ozone is manifested above $8 \mathrm{~km}$. The signals are statistically significant in the region $18-23 \mathrm{~km}$, reaching the maximum of $4 \mathrm{nbar}$ at the height of $20 \mathrm{~km}$. The transitional layer is noticed at $16 \mathrm{~km}$. It separates tropospheric and lower stratospheric effects. Another one, situated at $28 \mathrm{~km}$, separates lower stratospheric and middle stratospheric effects. When crossing the transitions, the quasibiennial anomalies reverse their phase. Between the transitions the ozone anomalies reveal downward propagation with the descent rate of about $0.6 \mathrm{~km} \cdot$ months $^{-1}$.

The quasi-biennial anomalies of temperature are not displayed so clearly as those of ozone, however, they reveal statistically significant signals at a number of heights located in the lower stratosphere and troposphere. The amplitudes of the anomalies vary in the range of $0.4-1{ }^{\circ} \mathrm{C}$.

The quasi-biennial signals of horizontal wind components monotonically change their phases with height. The meridional wind anomalies are maximum in the region $4-18 \mathrm{~km}$ and reveal the upward phase propagation, whereas the zonal wind anomalies reveal a hint on the downward phase propagation. Amplitudes of the signals are in the range of 1$2 \mathrm{~m} \cdot \mathrm{s}^{-1}$. 


\subsection{Antarctic}

The anomalies of ozone, temperature, and wind isolated at Syowa clearly display a quasi-biennial periodicity in the troposphere and stratosphere. The peaks of the ozone anomalies of about 4 nbar are noticed in the region $15-20 \mathrm{~km}$. The temperature anomalies reach the maxima of $1{ }^{\circ} \mathrm{C}$ at heights $19-22 \mathrm{~km}$. The anomalies of ozone and temperature are approximately in phase and reveal a hint of the downward propagation in the lower stratosphere. The anomalies display noticeable asymmetry, namely negative anomalies last a longer time than positive ones.

The phase relation between the horizontal wind components is such that wind oscillations have predominantly a NE-SW direction. Below $25 \mathrm{~km}$ the amplitudes of the wind anomalies are of about $1 \mathrm{~m} \cdot \mathrm{s}^{-1}$, but there is a hint that they are on the increase above this height.

It is seen that the phases of the quasi-biennial anomalies of all the parameters are synchronously changed with height which assumes a strong correlation between ozone, temperature and wind components.

\section{Discussion}

There are three main arguments evidencing in favor of a conclusion that the obtained anomalies are the responses on the QBO: the anomalies were obtained with the help of the superimposed epoch method, in which certain phases of the equatorial wind $\mathrm{QBO}$ were used as the key-0 data; the obtained results agree with theoretical and model concepts about physical mechanisms of off-equatorial effects of the QBO in ozone and temperature; the obtained results agree with results of other observational studies concerning offequatorial effects of the QBO. However, it is necessary to clear the role of other sources in making the quasi-biennial signals' appearance. Generally speaking, some of these signals could be obtained accidentally, some of them could be the effects of the method applied, and finally, some of the signals could be generated by physical mechanisms unrelated to the equatorial QBO.

It follows from Table 1 that even at the stations with long periods of observations (Resolute, Hohenpeissenberg, Payern (ozone only), and Goose Bay) a number of QBO cycles synchronized with observations and, therefore, a number of possible QBO responses available for averaging does not exceed 14. Thus, a statistical provision of the averages is rather poor and the presented work is a descriptive phenomenological study rather than a statistical study. However, it is also clear that some of the obtained anomalies are not accidental formations. In particular, in the low stratosphere the major part of the anomalies of ozone and temperature are, for all appearance, real. Firstly, a part of them are statistically significant. Secondly, at the majority of sites the ozone anomalies are found to be approximately in phase in the region of heights $20-23 \mathrm{~km}$, while a part of the stratospheric temperature anomalies displays a similar downward propagation.
Thirdly, a positive correlation between the ozone and temperature anomalies observed at most of sites between 20 and $25 \mathrm{~km}$ agrees with theoretical concepts of physical mechanisms, which may be responsible for evolution of these parameters in the low stratosphere. Despite that the last two reasons are only indirect proofs of the reality of the anomalies, they can be hardly explained by chance.

Two aspects of the question of whether the obtained quasibiennial signals could result from the method applied were considered. Firstly, since averaging in the method is realized for the lags \pm 24 months relative to key- 0 data, whereas the period of the key- 0 data is on average of about 28 months, a strong separate anomaly characterized by lags more than +14 or less than -14 could be repeated twice in an average signal (before and after key-0 datum), producing, thereby, a false periodicity. It is clear that the risk of obtaining such false signals is higher at the stations with a short period of observations. In the study this problem was solved by testing of time series and removing the residuals whose amplitudes exceed three standard deviations. Secondly, a quasi-biennial periodicity could result from a quasi-regularity of sampling. To clear this point the following test was carried out. At each height residuals were replaced by random signals, having the same period, gaps, and standard deviation as corresponding residuals. The sets of random profiles, constructed on the basis of such random signals, were underwent the same procedure as the real profiles and the results were compared. The numerous comparisons (at each site for each parameter) revealed essential differences between the amplitudes, periods, vertical structures and coherence of signals obtained from real and random time series. A nearness between the amplitudes of real and imitative "average anomalies" was noticed in less than $1 \%$ of the cases. At that, the largest differences between them were noticed in the vicinity of the local height maxima of the QBO responses. Thus, most of the obtained anomalies are not the result of the method applied.

To clear up the question of whether among the obtained quasi-biennial signals there are those whose origin is unrelated to the equatorial QBO, the residuals were averaged relatively the E-W reverses of the equatorial zonal wind, occurring at different levels. If at some fixed height an average anomaly, obtained by averaging the residuals relatively 50-hPa key-0 data relates to the equatorial $\mathrm{QBO}$, then those obtained relatively $10,20,30$, and $70 \mathrm{hPa}$ key- 0 data have to reveal the same shifts as corresponding key-0 data do. When comparing the anomalies averaged relatively key- 0 data taken at different levels, it was found that this was the case. At that, not only major peculiarities of the verical structures of the anomalies but frequently their fine details were obtained to be very similar but shifted, as a whole, by lags close to those between the corresponding key-0 data. Thus, it is very likely that most parts of the obtained anomalies are of the same genesis and represent the responses on the equatorial QBO.

Differences between the QBO responses obtained at different sites can be attributed to a number of reasons. Firstly, they can be explained by the fact that ozonesonde records 
at different sites differ by errors of measurements, periods, gaps, number of sondes, etc. Secondly, the differences can reflect an inconstancy of characteristics of the equatorial QBO itself, whose period and amplitude change with time. Thus, from 1965 until 1998 the period varied from 23 to 34 months. Therefore, in the observations embracing different time intervals different responses can be expected. In this connection it is interesting to compare the QBO effects isolated at Berlin and Biscarrosse, whose records are approximately of the same duration (Table 1). The observations at Berlin (1966-1972) were synchronized with two complete cycles of the QBO. The period of the first cycle was 3334 months, while the period of the second one was 23-24 months. Thus, the QBO effects at Berlin could be a combination of the responses on the QBO of two substantially different periods. It is reasonable to suppose that the time scales of the responses could also be different and the average response appears to be blurred. On the contrary, the observations at Biscarrosse (1976-1982) were synchronized with two cycles of the QBO, approximately for the same period ( $\sim 29$ months), and it is very likely that the time scales of the responses were similar. Indeed, it is seen (Fig. 2) that the QBO effects are displayed at Biscarrosse more clearly than at Berlin. Thirdly, an interplay between the QBO and the annual cycle can also lead to differences. The effects of such an interplay must vary with space and time, due to varying phase interrelations between these phenomena. It is clear that due to the relative shortness of ozonesonde records and gaps occurring in them, the obtained QBO effects reflect specific phase interrelations between the QBO and the annual cycle, occurring during records, and are, therefore, to a certain extent unique. Another reason for the differences is associated with a seasonal dependence of the QBO effects (at least in ozone). The question is that at different stations the frequency of the ozonesonde launches was different in different seasons. Moreover, at several sites in individual seasons there were not launches at all. This means that the QBO effects at such stations are characteristic only for separate periods of the year and can differ from those obtained at the stations with regular sounding, conducting all year round. In particular, at Sapporo, Tateno and Kagoshima, there were not summer measurements in the period between 1978-1989 (Table 1). Therefore, the QBO effects at these sites reflect the anomalies manifesting mainly in the period from autumn to spring. Another situation was at high-latitude stations. Thus, at Resolute the number of sondes reaching the height of $25 \mathrm{~km}$ in summer was $30 \%$ more than that in winter and the difference increased with height. This means that the yearly mean QBO effect becomes more and more characteristic for the summer condition with height. The aforesaid causes most noticeably must reveal themselves between the stations with short time series of observations spanning different periods. At such stations the average responses are dominated by anomalies occurring in separate periods, and, therefore, may not be quasi-biennial at all. It is also necessary to notice that at every station, because a number of sondes reaching a certain height is diminished with height, the relative contribution of individual anomalies with an average signal increases with height. It is clear that the more responses are averaged, the lesser the role of the variations in the QBO period and specific phase combinations between the QBO and the annual cycle plays. It is seen from Fig. 2 that at least in ozone and temperature there is a tendency: the longer the time series, the clearer the anomalies. It is rather complicated to infer from the results the possible geophysical causes of the differences. However, regional differences of the QBO effects in total ozone were repeatedly mentioned in literature (e.g. Wilcox et al., 1977). Among possible causes of them are local peculiarities of the large-scale circulation influenced by orographic condition, stationary planetary waves, changes in the jet streams positions, etc. It is worth noticing that under such abundance of possible reasons for the differences, the most surprising is the fact that the QBO effects, nevertheless, reveal common features.

When discussing a degree of belief of the results it is necessary to take into account not only the statistical significance of the results but also some physical considerations. The obtained results agree with the theoretical concepts about possible mechanisms of influence of the equatorial QBO. In particular, the quasi-biennial signals of temperature obtained in the tropics and subtropics agree with a theory of lowlatitude QBO and its models. It is generally accepted that the westerly (easterly) shear of the equatorial stratospheric zonal wind, through the thermal wind balance, is accompanied by a warming (cooling) of the equatorial stratosphere. To maintain the temperature disturbances in the presence of radiative damping, the meridional circulation arises with downward (upward) motion on the equator and upward (downward) motion in the subtropics (Reed, 1964; Plumb and Bell, 1982). The equatorial and subtropical branches of the QBOinduced circulation are separated by nodal lines situated approximately at $10^{\circ} \mathrm{N}$ and $10^{\circ} \mathrm{S}$. Because the low-latitude ozonesonde stations used in this work are located poleward of the nodal lines (Fig. 1), the negative quasi-biennial anomalies of temperature, manifesting in the stratosphere at these stations, should coincide with the westerly shear of the equatorial stratospheric zonal wind. Taking into account that over the equator the 50-hPa pressure level is at a height of about $20.5 \mathrm{~km}$, as well as that in the layer $70-10 \mathrm{hPa}(\sim 18-$ $32 \mathrm{~km}$ ) maximum westerly shears correspond approximately to the E-W phase reverses, and, therefore, descend with the rate of about $1 \mathrm{~km} \cdot \mathrm{month}^{-1}$ (e.g. Huesmann and Hitchman, 2001). One can deduce that the maximum negative temperature anomalies found between 20 and $30 \mathrm{~km}$ at Naha, Kagoshima, Tateno, and Wallops Island coincide with the corresponding westerly shear maxima of the equatorial wind. On the other hand, such a coincidence can also be traced at several mid-latitudinal stations, where the temperature anomalies reveal downward propagation, namely at Hohenpeissenberg, Payern, Lindenberg, Biscarrosse, and Sapporo. This fact evidences that the direct QBO circulation influences stratospheric temperature over Europe, Japan, and the USA. This inference is in tune with the results of the UKMO analysis done by Randel et al. (1999), who demonstrated, 
in particular, that in 1993-1994 the return branch of the QBO-induced circulation extended up to $50^{\circ} \mathrm{N}-\mathrm{S}$ (see their Fig. 18). At several stations without downward propagation of the temperature anomalies, the above-mentioned relationship between equatorial wind shear and local stratospheric temperature can be seen in the lower stratosphere and only over Canada it is not evident. It is worth noticing that Canadian stations used in this work are situated poleward of $50^{\circ} \mathrm{N}$, and the discrepancy may reflect different physical mechanisms responsible for the low-latitude and highlatitude QBO effects. Kinnersley and Tung (1999) tested several possible mechanisms of the inducing of a stratospheric extratropical circulation anomaly by the equatorial $\mathrm{QBO}$ and concluded that in low and middle latitudes the main cause of the anomaly is the direct QBO circulation, while at high latitudes it is formed due to the modulation of the planetary wave potential vorticity flux by the QBO. The structures of the QBO effects in temperature found in the NCEP reanalysis by Huesmann and Hitchman (2001) are in tune with this inference. It can be deduced from their Fig. 12, that equatorward of $50^{\circ}$, the stratospheric quasi-biennial temperature anomalies gradually progress downward in time, whereas poleward of $60^{\circ}$ observed at different heights anomalies change in time synchronously, revealing column-like structures. The column-like structure of the QBO effect in temperature was also simulated in the model study of Tung and Yang (1994) (their Fig. 2), who explained this structure by the fact that the temperature anomalies are associated with a circulation anomaly, induced by planetary wave breaking affecting the broad stratospheric layer. The vertical structures of the temperature anomalies obtained in this work agree with the above results. From Fig. 2 it is seen that at most of the stations located equatorward of $50^{\circ} \mathrm{N}$ the temperature anomalies are characterized by the downward propagation, whereas at most of the sites situated poleward of $50^{\circ} \mathrm{N}$ the temperature anomalies are characterized by a column-like structure. Huesmann and Hitchman (2001) also noted a tendency for strong quasi-biennial temperature perturbations just above the equator tropopause to be accompanied by weaker, opposite perturbations just below it. Similar tendencies of the QBO effects of temperature can be observed at a number of off-equatorial stations (Fig. 2). This feature is most clearly seen at Goose, where the effects in lower stratosphere and troposphere are in opposite phases.

The vertical structures of the QBO effects of ozone and temperature obtained at Hilo agree with the model results of Ling and London (1986), who showed that in the tropics the QBO signals in ozone and temperature must be out of phase between 30 and $35 \mathrm{~km}$, but in phase below $28 \mathrm{~km}$. The different correlation between the ozone and temperature signals in the low and middle stratosphere the authors explained by switching from the photochemical control of the ozone budget to a regime dominated by transport processes. They argued that the ozone signal in the photochemically controlled region was due to the effect of the temperature signal on the rates of the reactions controlling the ozone destruction. Also, the authors found that the ozone QBO must have the local maxima at the heights of 22 and $32 \mathrm{~km}$. It can be seen from Fig. 2 that at Hilo the anomalies of ozone and temperature are indeed in phase in the region $18-26 \mathrm{~km}$ and in opposite phase above $27 \mathrm{~km}$, as well as that at the heights of 23 and $30 \mathrm{~km}$ where the local maxima of the ozone anomalies are situated. However, it is necessary to note that the rate of descent of the temperature anomalies is less than that at the equator, used in the model, that may be because Hilo is located not far from the nodal line and, therefore, the direct QBO circulation here is characterized by smaller vertical velocities in the stratosphere, as compared with those at cites situated near the equator or far poleward. The amplitudes of the stratospheric ozone anomalies at Hilo may be compared with the results of Chipperfield et al. (1994), who isolated the ozone QBO using SAGE II data. In that paper the percentage ozone QBO effect obtained at the height of $24.5 \mathrm{~km}$ at latitude $20^{\circ} \mathrm{N}$ is about $3 \%$. At the same height at Hilo the percentage ozone anomaly amounts to $2.3 \%$ (the yearly mean ozone partial pressure at this height is about 130 nbar).

An existence of the transitional layer, separating the lowerand middle-stratospheric signals, leads to a so called "twocell" structure of the stratospheric QBO effects of ozone obtained by Zawodny and MacCormick (1991) at the equator and by Randel and Wu (1996) in the mid-latitudes. The above two studies used satellite data of the SAGE II instrument and, therefore, were limited by heights of $\sim 20-45 \mathrm{~km}$. This study deals with the range of heights from the ground up to $30-35 \mathrm{~km}$, and it can be seen (Fig. 2) that at most of the stations there is also a rather well-defined transitional layer located between 15 and $20 \mathrm{~km}$ and a hint of the existence of another one located in the troposphere (e.g. at Resolute, Goose, Hilo, etc.). Between the transitions the local maxima of the ozone quasi-biennial signals are situated. Thus, it seems that the layered structure is a peculiarity of the vertical structure of the QBO effects of ozone.

In the lower stratosphere the region of well-developed quasi-biennial ozone anomalies collocates with the region of the large vertical gradients of ozone. Taking into account that the photochemical relaxation times of ozone in this region is relatively long, the QBO effects of ozone in the lower stratosphere may be explained by quasi-biennial modulation of the vertical ozone advection (see also Bowman, 1989; Randel and $\mathrm{Wu}, 1996)$. In low latitudes such a modulation may be the result of a direct influence of the return branch of the QBO-induced circulation, while in high latitudes it may be the result of the anomalous quasi-biennial circulation, induced by planetary wave breaking, driven by the equatorial QBO. Whichever of the above mechanisms forces the vertical advection of ozone, the result seems to be similar and it is very likely that in middle latitudes both the mechanisms operate at the same time. In the middle stratosphere the physical mechanism of the quasi-biennial periodicity of ozone is different. Zawodny and McCormick (1991) found the quasibiennial signals of $\mathrm{NO}_{2}$ between 25 and $40 \mathrm{~km}$, and Chipperfield et al. (1994) inferred that namely these signals are the main cause of the quasi-biennial signals of ozone in the middle stratosphere. Randel and $\mathrm{Wu}$ (1996) found in this region 
strong negative ozone- $\mathrm{NO}_{2}$ correlation with an abrupt lower boundary sloped to the pole (their Fig. 18) and deduced that in turn the quasi-biennial signals of $\mathrm{NO}_{2}$ in the middle stratosphere may be due to transport variations. The results presented in this paper are in tune with these findings. It can be seen from Fig. 2 that at several stations there is a hint of the downward propagation of the ozone, anomalies above $30 \mathrm{~km}$ that may be associated with the $\mathrm{NO}_{2}$ transport. Also, the regions of the lower stratospheric and middle stratospheric quasi-biennial anomalies of ozone as well as the transition between them, indeed reveal a tendency to be lowered with latitude. Such a tendency can also be seen in the latitudeheight structure of the ozone anomalies caused by the QBO, derived from SAGE II data by Kinnersley and Tung (1999) (their Fig. 5b). Worthy of note is the fact that integrated over all heights the anomalies of the ozone partial pressure agree well with the QBO effects documented in total ozone content (e.g. Bowman, 1989).

An important point of the obtained results is the existence of the tropospheric quasi-biennial signals, as well as their relation to corresponding stratospheric phenomena. Obtained with the help of ozonesonde data the yearly mean tropopause positions are: $\sim 9 \mathrm{~km}$ at Alert, Resolute, and Syowa (the polar tropopause), $\sim 12 \mathrm{~km}$ at Berlin, Legionovo, Lindenberg, Hohenpeissenberg, Payern, Biscarrosse, Churchill, Goose, and Edmonton (the mid-latitudinal tropopause), $\sim 17-18 \mathrm{~km}$ at Tateno, Kagoshima, Naha, and Hilo (the tropical tropopause). At Cagliari/Elmas, Boulder, Wallops Island, Sapporo, and Laverton both the midlatitudinal and tropical tropopauses are manifested in the yearly mean temperature profiles. Thus, it is seen that the quasi-biennial signals also appear in the troposphere (Fig. 2), being, for the most part, insignificant (only the anomalies of ozone at Hilo, of temperature at Goose, of meridional wind at Legionovo and Lindenberg, and of the zonal and meridional winds at the Payern are significant at a number of adjacent heights). In general, the tropospheric quasi-biennial signals reveal more differences as compared with lower stratospheric signals.

There are several repeating types of mutual disposition of the tropospheric and stratospheric quasi-biennial anomalies. At a number of sites the tropospheric anomalies look like prolongation of the lower-stratospheric anomalies or vice versa (e.g. ozone at Resolute or temperature at Payern). Most of the tropospheric temperature anomalies are nearly in opposite phase with the lower-stratospheric anomalies (the most striking example is the temperature QBO at Goose). Also, it is seen that, if the wind reveals the maximum near the tropopause, its upper-tropospheric anomalies are nearly in phase with lower-stratospheric anomalies (e.g. the meridional wind QBO at Lindenberg). Unfortunately, only the stratospheric and tropospheric anomalies of temperature at Goose and those of meridional wind at Legionovo and Lindenberg coexist to be statistically significant. Thus, on the basis of the obtained results it is hardly possible to infer a certain relationship between the tropospheric and stratospheric quasi-biennial anomalies, and this question needs further study. Taking into account this fact and also that some authors showed that the tropospheric variability on the time scales from 2 to 3 years may be the result of a tropical atmosphere ocean interaction (e.g. Meehl, 1993) or multiscale interactions (e.g. Goswami, 1995), the question arises as to whether the obtained tropospheric signals are the effect of the equatorial QBO or they are produced by another mechanisms. To answer this question it is necessary to take into consideration the fact that the phase differences between stratospheric and tropospheric quasi-biennial anomalies obtained by averaging of the residuals in their relation to key- 0 data taken at different levels are approximately the same. This fact evidences in favor of correlation of the stratospheric and tropospheric anomalies. Therefore, it may be supposed that the mechanisms of generation of the quasi-biennial oscillations in the troposphere and stratosphere are synchronized, and it is very likely that both mechanisms have the same fundamental cause - equatorial QBO. Near the tropopause a local minimum of the quasibiennial signals occurs frequently. The minimum is often accompanied by the phase shift of the signals. This peculiarity is more noticeable in temperature, but at several sites it may also be found in ozone and wind. It is seen (Fig. 2) that at high-latitudinal stations and at several mid-latitudinal stations the quasi-biennial anomalies of ozone can penetrate through the tropopause from the low stratosphere to the troposphere (e.g. at Resolute, Goose). This fact evidences that the quasi-biennial variability of ozone is a component of the stratospheric-tropospheric exchange of ozone. Also, it can be seen that the lower stratospheric transitions noticed in the vertical structures of the quasi-biennial signals of ozone at a number of mid-latitudinal stations, for example, at Hohenpeissenberg and Payern collocate at the position of the tropical tropopause. It is interesting to trace the changes in the vertical structures of the ozone and temperature anomalies, observed at the Japanese stations. While the height of the tropical tropopause obtained at these stations is approximately the same $(\sim 17-18 \mathrm{~km})$, the tropopause temperatures are different, being equal to $-56^{\circ} \mathrm{C}$ at Sapporo, $-64^{\circ} \mathrm{C}$ at Tateno, $-69^{\circ} \mathrm{C}$ at Kagoshima, and $-75^{\circ} \mathrm{C}$ at Naha. When comparing the vertical structures of the anomalies one can see that a boundary, separating the stratospheric and tropospheric signals, becomes more noticeable with the decrease in the tropopause temperature. It is necessary to notice that at some stations, at which observations are rather long and contain few gaps, the vertical structures of the anomalies obtained by the superimposed epoch method agree with vertical structures of the quasi-biennial signals obtained with the help of spectral analysis. An accordance of the results of two independent methods (Sitnov and Bezverkhny, 2000) evidences for the reality of the results of both studies. 


\section{Conclusion}

The QBO effects, manifesting in ozone, temperature and horizontal wind components as variability of these parameters on the equatorial QBO period (24-32 months) are distinctly seen both in the stratosphere and in the troposphere, in low, middle and high latitudes of the Northern Hemisphere, as well as in Australia and Antarctic.

The vertical structures of the QBO effects of ozone are represented as an alternation of layers of well-developed quasi-biennial signals, whose phases gradually change with height, and layers of ill-developed signals, whose phases often change abruptly with height. At the majority of sites the quasi-biennial signals (or, in other words, the quasi-biennial anomalies) are found to be approximately in phase between 20 and $23 \mathrm{~km}$. The amplitudes of the anomalies depend on height and reach the maxima of 3-6 nbar in the lower stratosphere. Inasmuch as isolated QBO effects are yearly means (the anomalies were averaged without regard to a season), whereas it is known that the QBO effects in columnar ozone are seasonally dependent to be the strongest in a cold period, the anomalies falling on a cold period, to all appearances, can be greater.

Two types of the vertical structures of the temperature QBO effects are found. At most of sites located equatorward of about $50^{\circ}$ the stratospheric temperature anomalies are characterized by downward propagation, whereas at sites situated poleward of about $50^{\circ}$ the anomalies are characterized by column-like structures (the exceptions - Cagliari/Elmas and Australia can be partially explained by data shortages). Near the tropopause the effects frequently reveal dipole-like structures, when the stratospheric and tropospheric anomalies are of opposite signs. The amplitudes of the effects are in the range $0.5-1{ }^{\circ} \mathrm{C}$.

The vertical structures of the QBO effects of the horizontal wind components reveal a diversity of patterns. The amplitudes of the QBO effects of the meridional and zonal winds are comparable and lie in the range of $0.5-2 \mathrm{~m} \cdot \mathrm{s}^{-1}$. As a rule, the maxima of the effects are noticed slightly below the tropopause, as well as in the middle stratosphere.

Along with similarity obtained QBO effects reveal noticeable differences and the question about their nature still remains open. The differences can be attributed to a number of reasons. Firstly, they can be explained by the fact that ozonesonde records at different sites differ by periods, gaps, number of sondes, errors of measurements, etc. Secondly, the differences can be associated with an inconstancy of characteristics of the equatorial QBO itself, both with the amplitude and period. This fact can be an important reason for the differences between the stations, with short records covering different periods. Thirdly, an interplay between the QBO and the annual cycle can also lead to differences. The effects of such an interplay must vary with space and time, due to varying phase interrelations between these phenomena. It is clear that due to the relative shortness of ozonesonde records and the gaps occurring in them, the obtained QBO effects reflect specific phase interrelations between the $\mathrm{QBO}$ and the annual cycle occurring during records, and, therefore, are to a certain extent, unique. Another reason for the differences is associated with a seasonal dependence of the QBO effects. The point is that at different stations the frequency of ozonesonde launches was different in different seasons. Moreover, at several sites in individual seasons there were not launches alt all (Table 1). This means that the QBO effects at such stations are characteristic only for separate periods of the year and can differ from those obtained at the stations with regular sounding, conducting all year round. Finally, the differences can reflect real regional characteristics of the QBO effects associated with local peculiarities of the large-scale circulation influenced by local orographic conditions, stationary planetary waves, changes in the jet streams positions, etc.

Thus, the QBO responses obtained in this work reflect both general characteristics of the QBO effects and their peculiarities, manifesting in a separate region, within a separate period, conditioned in addition by peculiarities of individual ozonesonde records.

Acknowledgements. Updated QBO winds were kindly supplied by Dr. Barbara Naujokat. This work was supported by RFBR grant 01-05-64546, and partially, by RFBR grant 02-05-64167.

Topical Editor O. Boucher thanks J. Hampson and another referee for their help in evaluating this paper.

\section{References}

Angell, J. K. and Korshover, J.: Quasi-biennial variations in temperature, total ozone and tropopause height, J. Atmos. Sci., 21, 479-492, 1964.

Angell, J. K. and Korshover, J.: Biennial variation in springtime temperature and total ozone in extratropical latitudes, Mon. Weather Rev., 95, 757-762, 1967.

Baldwin, M. P., Gray, L. J., Dunkerton, T. J., Hamilton, K., Haynes, P. H., Randel, W. J., Holton, J. R., Alexander, M. J., Hirota, I., Horinouchi, T., Jones, D. B., Kinnersley, J. S., Marquardt, C., Sato, K., and Takahashi, M.: The quasi-biennial oscillation, Rev. Geophys., 39, 179-230, 2001.

Barnes, R. A., Bandy, A. R., and Torres, A. L.: Electrochemical concentration cell ozonesonde accuracy and precision, J. Geophys. Res., 90, 7881-7887, 1989.

Barnett, J. J. and Corney, M.: Middle atmosphere reference model derived from satellite data, in Handbook for MAP, vol. 16, pp. 47-85, SCOSTEP Secr., Univ. of Ill., Urbana, 1985.

Bowman, K. P.: Global pattern of the quasi-biennial oscillation in total ozone, J. Atmos. Sci., 46, 3328-3343, 1989.

Brewer, A. W. and Milford, J. R.: The Oxford-Kew ozone sound, Proc. R.. Soc. London A, 256, 470-495, 1960.

Chipperfield, M. P., Kinnersley, J. S., and Zawodny, J.: A twodimensional model study of the QBO signal in SAGE II $\mathrm{NO}_{2}$ and $\mathrm{O}_{3}$, Geophys. Res. Lett., 21, 589-592, 1994.

De Backer, H., De Muer, D., and De Sadelaer, G.: Comparison of ozone profiles obtained with Brewer-Mast and Z-ECC sensors during simultaneous ascents, J. Geophys. Res., 103, $19641-$ $19648,1998$.

Dunkerton, T. J. and Delisi, D. P.: Climatology of the equatorial lower stratosphere, J. Atmos. Sci., 42, 376-396, 1985. 
Dunkerton, T. J.: Quasi-biennial and subbiennial variations of stratospheric trace constituents derived from HALOE observations, J. Atmos. Sci., 58, 7-25, 2001.

Ebdon, R. A. and Varyard, R. G.: Fluctuations in equatorial stratospheric winds, Nature, 189, 791-793, 1961.

Goswami, B. N.: A multiscale interaction model for the origin of the tropospheric QBO, J. Clim., 8, 524-534, 1995.

Gray, L. J. and Pyle, J. A.: A two-dimensional model of the quasibiennial oscillation of ozone, J. Atmos. Sci., 46, 203-220, 1989.

Gray, L. J. and Russell III, J. M.: Interannual variability of trace gases in the subtropical winter stratosphere, J. Atmos. Sci., 56, 977-993, 1999.

Hamilton, K.: Effects of an imposed quasi-biennial oscillation in a comprehensive troposphere-stratosphere-mesosphere general circulation model, J. Atmos. Sci., 55, 2393-2418, 1998.

Hasebe, F.: The global structure of the total ozone fluctuations observed on timescales of two to several years, Dynamics of the Middle Atmosphere, edited by Holton, J. R., Matsuno, T., and Reidel, D., Norwell Mass., pp. 445-464, 1984.

Hasebe, F.: Quasi-biennial oscillation of ozone and diabatic circulation in the equatorial stratosphere, J. Atmos. Sci., 51, 729-745, 1994.

Hess, P. G. and O'Sullivan, D.: A three-dimensional modeling study of the extratropical quasi-biennial oscillation in ozone, J. Atmos. Sci., 52, 1539-1554, 1995.

Hollandsworth, S. M., Bowman, K. P., and McPeters, R. D.: Observational study of the quasi-biennial oscillation in ozone, J. Geophys. Res., 100, 7347-7361, 1995.

Holton, J. R. and Lindzen, R. S.: An updated theory for quasibiennial oscillation of the tropical stratosphere, J. Atmos. Sci., 29, 1076-1080, 1972.

Huesmann, A. S. and Hitchman, M. H.: The stratospheric quasibiennial oscillation in the NCEP reanalysis: Climatological structures, J. Geophys. Res., 106, 11 859-11 874, 2001.

Kinnersley, J. S. and Tung, K. K.: Mechanisms for extratropical QBO in circulation and ozone, J. Atmos. Sci., 56, 1942-1962, 1999.

Komhyr, W. D.: Electrochemical concentration cell gas analysis, Ann. Geophys., 25, 203-210, 1969.

Lait, L. R., Schoeberl, M. R., and Newman, P. A.: Quasi-biennial modulation of the Antarctic ozone depletion, J. Geophys. Res., 94, 11 559-11 571, 1989.

Lindzen, R. S. and Holton, J. R.: A theory of the quasi-biennial oscillation, J. Atmos. Sci., 25, 1095-1107, 1968.
Ling, X.-D. and London, J.: The quasi-biennial oscillation of ozone in the tropical middle stratosphere: A one-dimensional model, J. Atmos. Sci., 43, 3122-3137, 1986.

Logan, J. A.: Trends in the vertical distribution of ozone: An analysis of ozonesonde data, J. Geophys. Res., 99, 25 553-25 585, 1994.

Meehl, G. L.: A coupled air-sea biennial mechanism in the tropical Indian and Pacific regions: Role of the oceans, J. Clim., 6, 31-41, 1993.

Naujokat, B.: An update of the observed quasi-biennial oscillation of the stratosphere winds over the tropics, J. Atmos. Sci., 43, 1873-1877, 1986.

Panofsky, H. A. and Brier, G. W.: Some applications of statistics to meteorology, The Penn. State Univ., University Park, Pa., 224 pp., 1958.

Plumb, R. A. and Bell, R. C.: A model of the quasi-biennial oscillation on an equatorial beta-plane, Q. J. R. Meteorol. Soc., 108, 335-352, 1982.

Randel, W. J. and Wu, F.: Isolation of the ozone QBO in SAGE II data by singular-value decomposition, J. Atmos. Sci., 53, 25462559, 1996.

Randel, W. J., Wu, F., Swinbank, R., Nash, J., and O'Neill, A.: Global QBO circulation derived from UKMO stratospheric analyses, J. Atmos. Sci., 56, 457-474, 1999.

Reed, R. J.: A tentative model of the 26-month oscillation in tropical latitudes, Q. J. R. Meteorol. Soc., 90, 441-466, 1964.

Reed, R. J., Campbell, W. J., Rasmussen, L. A., and Rogers, D. G.: Evidence of a downward-propagating annual wind reversal in the equatorial stratosphere, J. Geophys. Res., 66, 813-818, 1961.

Sitnov, S. A. and Bezverkny, V. A.: Vertical structures of the QBO and El Niño effects in ozone, temperature, and wind in the northern extratropics, Proc. Quadr. Ozone Symp., Sapporo, Japan, 649-650, 2000.

Tung, K. K. and Yang, H.: Global QBO in circulation and ozone, II, A simple mechanistic model, J. Atmos. Sci., 51, 2708-2721, 1994.

Wilcox, R. W., Nastrom, G. D., and Belmont, A. D.: Periodic variations of total ozone and its vertical distribution, J. Appl. Meteorol., 16, 290-298, 1977.

Zawodny, M. J. and McCormick, M. P.: Stratospheric Aerosol and Gas Experiment II measurements of the quasi-biennial oscillations in ozone and nitrogen dioxide, J. Geophys. Res., 96, 93719377, 1991. 